\title{
Earth-abundant amorphous catalysts for electrolysis of water
}

\author{
Wence $\mathrm{Xu}^{\mathrm{a}, \mathrm{b}}$, Hongxia Wang $\mathrm{a}, *$ \\ a School of Chemistry, Physics and Mechanical Engineering, Queensland University of Technology, QLD4001, Brisbane, Australia \\ b School of Materials Science and Engineering, Tianjin University, Tianjin 300072, China
}

\section{A R T I C L E I N F O}

\section{Article history:}

Received 30 January 2017

Accepted 28 February 2017

Published 5 June 2017

\section{Keywords:}

Amorphous catalyst

Non-noble metal material

Hydrogen evolution reaction

Oxygen evolution reaction

Overall water splitting

\begin{abstract}
A B S T R A C T
The generation of hydrogen through the electrolysis of water has attracted attention as a promising way to produce and store energy using renewable energy sources. In this process, a catalyst is very important to achieve a high-energy conversion efficiency for the electrolysis of water. A good catalyst for water electrolysis should exhibit high catalytic activity, good stability, low cost and good scalability. Much research has been devoted to developing efficient catalysts for both the hydrogen evolution reaction (HER) and oxygen evolution reaction (OER). Traditionally, it has been accepted that a material with high crystallinity is important to serve as a good catalyst for HER and/or OER. Recently, catalysts for HER and/or OER in the electrolysis of water splitting based on amorphous materials have received much interest in the scientific community owing to the abundant unsaturated active sites on the amorphous surface, which form catalytic centers for the reaction of the electrolysis of water. We summarize the recent advances of amorphous catalysts for HER, OER and overall water splitting by electrolysis and the related fundamental chemical reactions involved in the electrolysis of water. The current challenges confronting the electrolysis of water and the development of more efficient amorphous catalysts are also discussed.
\end{abstract}

(C) 2017, Dalian Institute of Chemical Physics, Chinese Academy of Sciences. Published by Elsevier B.V. All rights reserved.

\section{Introduction}

Modern society is driven by a myriad of energy-demanding electronic devices owing to the advancements of science and technology. The main energy sources are still based on fossil fuels that have limited reserves. Moreover, the consumption of coal, oil and natural gas has caused environmental pollution, greenhouse gas emission and global warming, which can result in natural disasters and other catastrophes. Therefore, it is important to develop sustainable energy by developing alternative energy supplies that are clean and abundant. Wind and solar power are regarded as the primary renewable energy sources. However, the energy supplied by these technologies is not stable and is strongly dependent on the regional variability of solar light and wind. Transforming these unstable energy sources into more stable hydrogen energy through the elec- trolysis of water splitting may enable a more secure and clean-energy future because hydrogen can be subsequently reconverted into electricity through fuel cells $[1,2]$. Electrolysis of water provides an excellent adaptability to the environment and can efficiently produce hydrogen (and oxygen) from the intermittent energy source through electrochemical energy devices.

The history of the technology of the electrolysis of water can be dated back to 1789 when Deiman and Troostwijk first transformed water into hydrogen and oxygen with a Leyden jar [3]. Through this method, very high-purity hydrogen ( $\approx 100 \%$ ) can be produced [4]. The process of water electrolysis can be divided into two half-cell reactions; that is, the cathode reaction for the hydrogen evolution reaction (HER) and the anode reaction for the oxygen evolution reaction (OER). The energy conversion efficiency of both HER and OER is very low under a

\footnotetext{
* Corresponding author. Tel: +61-7-31381984; Fax: +61-7-31388381; E-mail: hx.wang@qut.edu.au

DOI: 10.1016/S1872-2067(17)62810-9 | http://www.sciencedirect.com/science/journal/18722067 | Chin. J. Catal., Vol. 38, No. 6, June 2017
} 
direct electrolysis of water because of the high-energy barrier for the reduction of $\mathrm{H}^{+}$and oxidation of $\mathrm{O}^{2-}$ in a water molecule. Therefore, different types of catalysts to facilitate both HER and OER have been developed. To date, both the HER and OER are generally catalyzed by metal-based catalysts, such as $\mathrm{Pt}, \mathrm{Ru}$ and Ir, and their oxides. However, the low reserve and high cost of noble metals greatly reduce their practical applications. Hence, it is highly important to develop alternative catalysts that possess excellent catalytic activity and stability but at a low price [5-8].

However, the standard oxidation potential of the OER of water is $1.23 \mathrm{~V}$ (vs standard hydrogen electrode (SHE) at standard temperature and pressure $\left.\left(25^{\circ} \mathrm{C}, 0.1 \mathrm{MPa}\right)\right)$. However, in the practical water electrolysis process, an excess potential (also known as overpotential, $\eta$ ) is normally required to overcome the intrinsic activation barriers, which leads to sluggish kinetics and poor energy efficiency at both the anode and cathode as well as other side reactions that contribute to the overpotential $[5,9]$. Thus, the practical operational voltage $\left(E_{\mathrm{op}}\right)$ for water splitting can be described as [10]:

$$
E_{\text {op }}=1.23 \mathrm{~V}+\eta_{\mathrm{a}}+\eta_{\mathrm{c}}+\eta_{\text {other }}
$$

where $\eta_{\mathrm{a}}, \eta_{\mathrm{c}}$ and $\eta_{\mathrm{other}}$ are the intrinsic activation barriers of the anode, cathode and other resistances, respectively. Among these activation barriers, $\eta_{\text {other }}$ can be reduced by optimizing the design of the electrolytic cell, whereas $\eta_{\mathrm{a}}$ and $\eta_{\mathrm{c}}$ can only be reduced by increasing the catalytic activity of the catalysts towards HER and OER, respectively. Hence, it is highly desirable to develop catalysts for efficient water splitting to make this technology commercially attractive.

It is well known that the catalytic activity of a catalyst is significantly affected by the density of active sites. Confining catalysts to the nanoscale may lead to a higher catalytic activity because the nanosized catalysts can effectively enlarge the surface area and thus increase both mass transfer and the exposure of active sites for HER and/or OER to enhance the reaction rate, which leads to a lower overpotential for water splitting. Owing to the high conductivity, controllable active facet and nanostructure, crystal catalysts (such as metal sulfides [11], phosphides [12], carbides [13], oxides [14,15] and hydroxides [16]) have been widely developed. The common strategies for the design of crystal catalysts with high density of active sites are facet engineering, nanoscale, polymorph engineering and interface engineering [17]. It is generally accepted that amorphous catalysts with a disordered atomic arrangement are more active but less stable than crystalline counterparts [18]. However, increasing evidence has suggested that amorphous materials may have unique advantages in the application of electrocatalysts. The amorphous state creates abundant coordinatively unsaturated sites on the surface, which act as catalytic centers in electrocatalytic applications although the absence of long-range order in an amorphous material may not favor their electronic and photonic properties [19,20]. In addition, compared with a crystalline material with fixed atomic ratio, the composition of amorphous materials can be adjusted, which greatly expands the scope to design catalysts with an optimum content. Moreover, the fabrication of amorphous material normally requires mild conditions with low-cost precur- sors, which will dramatically decrease the fabrication cost.

Herein, we briefly review the recent progress on catalysts for the electrolysis of water using earth-abundant elements with a particular focus on the material and structural engineering of amorphous catalytic materials. General strategies for the design of amorphous HER and OER catalysts are summarized, and the advantages and drawbacks of these methods are discussed. Finally, we present a perspective on the future of electrocatalysts for HER and OER. With these, we hope to provide readers with an overview of this rapidly evolving field.

\section{Fundamentals of water electrolysis}

HER is one of the most well-studied electrochemical reactions. A good understanding of the HER mechanism is undoubtedly necessary to guide the fabrication of efficient HER catalysts. The chemical reactions involved in the HER process are expressed below according to the different type of electrolytes [9]:

In an acidic solution:

$$
\begin{aligned}
& 2 \mathrm{H}^{+}+2 \mathrm{e}^{-} \rightarrow \mathrm{H}_{2} \\
& \text { In an alkaline solution: } \\
& 2 \mathrm{H}_{2} \mathrm{O}+2 \mathrm{e}^{-} \rightarrow \mathrm{H}_{2}+2 \mathrm{OH}^{-}
\end{aligned}
$$

The HER kinetics are strongly dependent on the $\mathrm{pH}$ value and its reaction pathway. Especially, the pathway is influenced by both the catalyst and potential. In acidic solution, HER generally involves three possible reaction steps. The first step is hydrogen adsorption caused by proton-coupled electron transformation at the surface of a catalyst, which is called the Volmer step:

$$
\mathrm{H}_{\mathrm{aq}}{ }^{+}+\mathrm{e}^{-} \rightarrow \mathrm{H}_{\mathrm{ads}}
$$

After this, there are two possibilities for the adsorbed hydrogen atom where it can either react with a proton from the electrolyte accompanied with an electron from hydrogen or recombine with another adsorbed hydrogen atom to form a hydrogen molecule. The former process is known as the Heyrovsky step (electrochemical desorption step) with the reaction as:

$$
\mathrm{Hads}+\mathrm{Haq}^{+}+\mathrm{e}^{-} \rightarrow \mathrm{H}_{2}
$$

The latter process is called the Tafel step and can be described as:

$$
\mathrm{H}_{\mathrm{ads}}+\mathrm{H}_{\mathrm{ads}} \rightarrow \mathrm{H}_{2}
$$

Clearly, both reactions involve $\mathrm{H}_{\text {ads. }}$. Hence the free energy of hydrogen adsorption is widely accepted to be a descriptor for a hydrogen-evolving material [4].

In an alkaline electrolyte, the formation of $\mathrm{H}_{2}$ also involves three steps. However, the Volmer step and Heyrovsky step are different compared with the HER in acidic electrolyte solution [21]. Owing to the low concentration of protons, the hydrogen absorption is caused by a combination of molecular $\mathrm{H}_{2} \mathrm{O}$ with an electron instead of direct absorption of a proton:

$$
\mathrm{H}_{2} \mathrm{O}+\mathrm{e}^{-} \rightarrow \mathrm{H}_{\mathrm{ads}}+\mathrm{OH}^{-}
$$

In the Heyrovsky step, the absorbed hydrogen further reacts with molecular $\mathrm{H}_{2} \mathrm{O}$ and an electron to form a hydrogen molecule:

$$
\mathrm{H}_{\mathrm{ads}}+\mathrm{H}_{2} \mathrm{O}+\mathrm{e}^{-} \rightarrow \mathrm{H}_{2}+\mathrm{OH}^{-}
$$


tion of $\mathrm{OH}$ and $\mathrm{O}$ species on the catalyst surface in both acidic and alkaline conditions are shown in Eqs. 9 and 10, respectively. The overall reaction overpotential is commonly thought to be dependent on the kinetic constraints of the individual reaction steps [22]. In acidic solution, the most recognized mechanisms are the oxide path (Eq. 11) and the electrochemical oxide path (Eqs. 12 and 13)[23]:

$$
\begin{gathered}
\mathrm{H}_{2} \mathrm{O} \rightarrow \mathrm{OH}_{\mathrm{ads}}+\mathrm{H}^{+}+\mathrm{e}^{-} \\
\mathrm{OH}_{\text {ads }} \rightarrow \mathrm{O}_{\text {ads }}+\mathrm{H}^{+}+\mathrm{e}^{-}
\end{gathered}
$$

For the oxide path:

$$
\mathrm{O}_{\text {ads }}+\mathrm{O}_{\mathrm{ads}} \rightarrow \mathrm{O}_{2}
$$

For the electrochemical oxide path

$$
\begin{gathered}
\mathrm{O}_{\text {ads }}+\mathrm{H}_{2} \mathrm{O} \rightarrow \mathrm{OOH}_{\mathrm{ads}}+\mathrm{H}^{+}+\mathrm{e}^{-} \\
\mathrm{OOH}_{\mathrm{ads}} \rightarrow \mathrm{O}_{2}+\mathrm{H}^{+}+\mathrm{e}^{-}
\end{gathered}
$$

In an alkaline solution, the initial steps start with the adsorption of hydroxide ions on the catalytically active site (Eqs. 14 and 15) [4,24]:

$$
\begin{gathered}
\mathrm{OH}^{-} \rightarrow \mathrm{OH}_{\mathrm{ads}}+\mathrm{e}^{-} \\
\mathrm{OH}_{\mathrm{ads}}+\mathrm{OH}^{-} \rightarrow \mathrm{O}_{\mathrm{ads}}+\mathrm{H}_{2} \mathrm{O}+\mathrm{e}^{-}
\end{gathered}
$$

For the electrochemical oxide path, the adsorbed $\mathrm{O}_{\text {ads }}$ reacts with a hydroxide ion to form intermediate $00 H_{a d s}$ (Eq. 16), which is subsequently combined with another hydroxide ion to produce $\mathrm{O}_{2}$ (Eq. 17).

$$
\begin{gathered}
\mathrm{O}_{\mathrm{ads}}+\mathrm{OH}^{-} \rightarrow \mathrm{O}_{2}+\mathrm{H}_{2} \mathrm{O}+\mathrm{e}^{-} \\
\mathrm{OOH}_{\mathrm{ads}}+\mathrm{OH}^{-} \rightarrow \mathrm{O}_{2}+\mathrm{H}_{2} \mathrm{O}+\mathrm{e}^{-}
\end{gathered}
$$

At constant temperature, the reaction rates of HER and OER depend on the elementary reaction step that has the slowest reaction rate, which is defined as the rate-determining step [5]. The Tafel slope is widely used as an indicator to detect the rate-determining step. For example, the Tafel slopes of $\sim 30$, $\sim 40$ and $120 \mathrm{mV} / \mathrm{dec}$ represent the rate-determining steps for the Tafel step, Heyrovsky step and Volmer step in acidic solution, respectively. However, the Tafel slope is influenced by many other factors such as the applied potential, the absorption of other molecules and mass transport in porous structures [4]. The free energy of hydrogen adsorption $\left(\Delta G_{H}\right)$ is widely employed to evaluate the catalytic performance of a catalyst for HER [7]. Fig. 1 shows the volcano plot of the HER catalyst. In the case of a positive $\Delta G_{\mathrm{H}}$, $\mathrm{H}_{\text {ads }}$ strongly adsorbs on

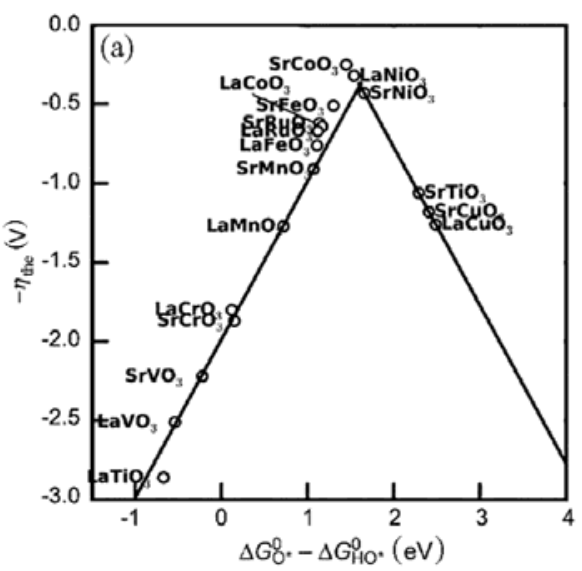

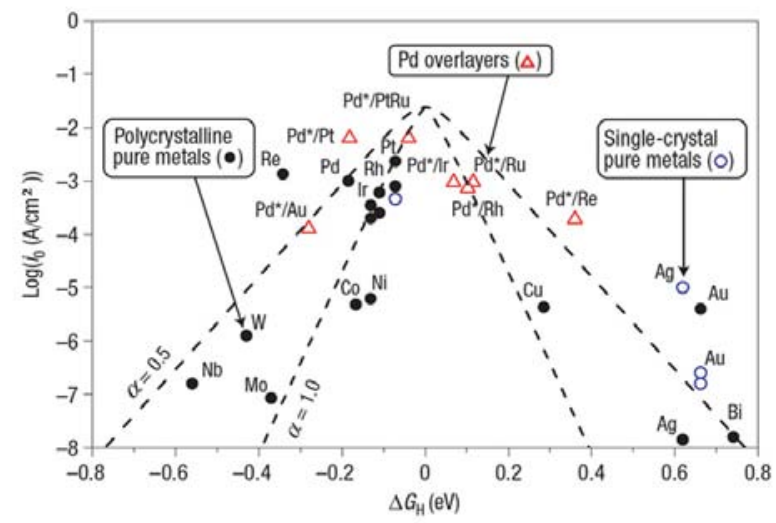

Fig. 1. Volcano plot of various pure metals and metal overlayers for HER. Reproduced with permission from Ref. [11].

the active site, making it hard to release a hydrogen molecule. Therefore, the Tafel or Heyrovsky step is the rate-determining step. If the $\Delta G_{H}$ is negative, $H_{\text {ads }}$ has a weak interaction with the active site. As a result, the absorption of a hydrogen atom limits the overall turnover rate, and, hence, the Volmer step is the rate-determining step [25]. In terms of OER, the difference between the energy states of the two subsequent intermediates ( $\Delta G^{\circ}{ }_{\text {OOHads }}-\Delta G^{\circ}{ }_{\text {OHads }}$ ) is widely used as the descriptor to evaluate the catalytic activity of the catalyst [5]. The corresponding volcano plot is shown in Fig. 2. In the case that the bonding between the adsorbed oxygen and the active site is strong, the potential is limited by the formation of the $\mathrm{OOH}_{\text {ads }}$ species. In the opposite case, the interaction between adsorbed oxygen and the active site is weak, which will limit the oxidation of $\mathrm{OH}_{\text {ads }}$ [24]. Therefore, a catalyst should have optimized energy states and surface properties to minimize the energy barrier for the rate-determining steps in both HER and OER.

\section{Electrocatalysts for HER}

The availability of active sites has been considered to be one of the most important factors for HER catalysts. The synthesis of amorphous catalysts is an efficient way to increase the den-

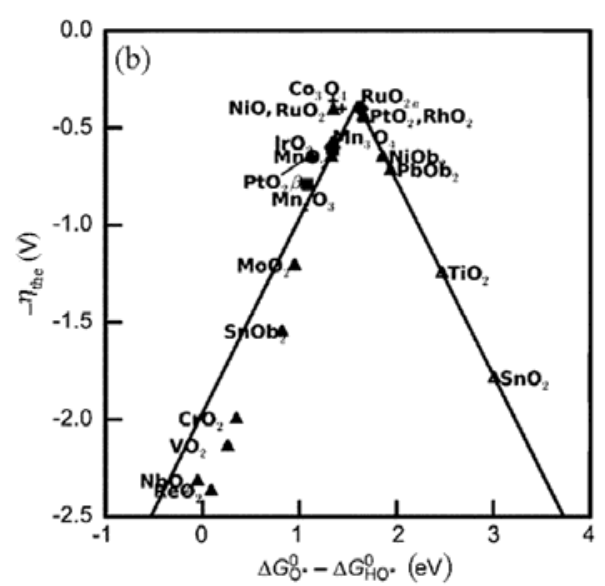

Fig. 2. Activity trends of various perovskites (a) and rutile, anatase, $\mathrm{Co}_{3} \mathrm{O}_{4}$, and $\mathrm{Mn}_{x} \mathrm{O}_{y}$ oxides (b). For perovskites, the negative theoretical overpotential was plotted against the standard free energy of the $\Delta G^{\circ}{ }_{0^{*}}-\Delta G^{\circ} \mathrm{HO}^{*}$ step. For oxides, the negative values of the theoretical overpotential were plotted against the standard free energy of the $\Delta G^{\circ} \mathrm{HO}^{*}-\Delta G^{\circ} \mathrm{O}^{*}$ step. Reproduced with permission from Ref. [17]. 
sity of active sites for high catalytic activity in the electrolysis of water. Although the disordered or short-range atomic arrangement is detrimental to their electronic and photonic properties, a large amount of coordinatively unsaturated sites, which serve as catalytic centers in HER, is definitely highly desirable for catalytic applications $[17,26,27]$. In addition, amorphous materials are normally prepared at milder temperature and involve faster solidification processes with low-cost precursors, which make them attractive for the development of cost-effective catalysts [28]. Among the various amorphous HER catalysts, amorphous molybdenum sulfides are regarded as the most promising HER catalysts and have been extensively studied $[17,28,29]$.

\subsection{Molybdenum sulfide catalysts}

The fabrication of amorphous molybdenum sulfides has a long history, where Jacobson et al. [30] first used amorphous molybdenum trisulfide as the lithium battery cathode. However, their application for HER has only been discovered in the past few years [31]. Structural measurements demonstrate that amorphous molybdenum sulfides are sulfur-rich in composition, and the abundant sulfur atoms can form disulfide bonds that are unsaturated in coordination $[27,32]$. The unsaturated sulfur atoms can act as active sites to catalyze the HER process [17]. These materials are usually prepared at milder temperature and with faster solidification processes, such as electrodeposition and wet chemical reaction [19,20,33,34]. Hu's group $[19,35]$ has performed research on the synthesis and applica-
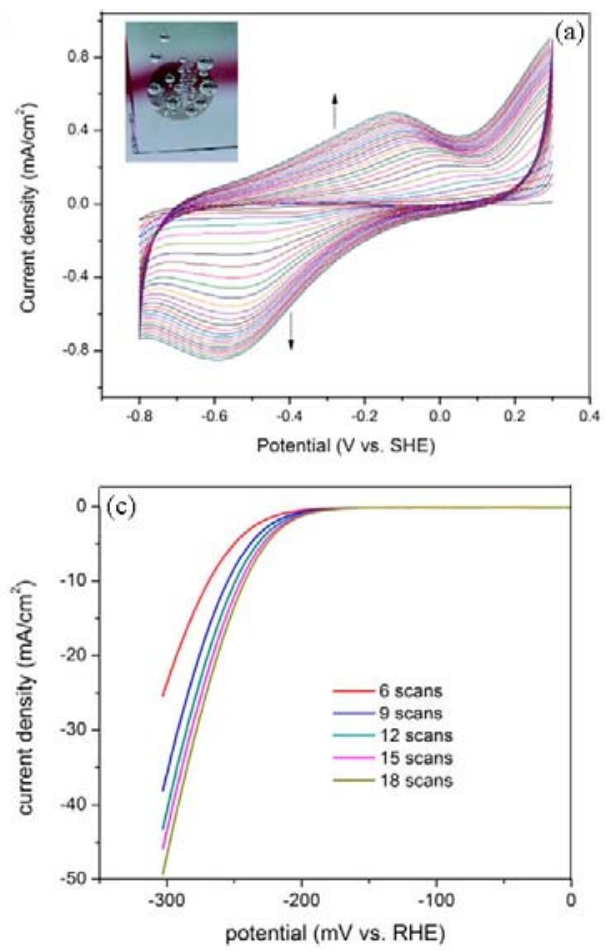

tion of amorphous molybdenum sulfides. As shown in Fig. 3, they first fabricated an amorphous molybdenum sulfide layer on various substrates by an electrodeposition method and further studied the growth mechanism. This material exhibited good catalytic activity over a wide pH range. They further improved the chemical synthesis method for $\mathrm{MoS}_{3}$ by acidification of a solution of $\mathrm{MoO}_{3}$ and $\mathrm{Na}_{2} \mathrm{~S}$, making the synthesis more economical [34]. Besides Hu's group, Jaramillo and co-workers [35] presented a scalable wet chemical synthesis for an amorphous molybdenum sulfide material. After 10,000 reductive potential cycles, the overpotential required for a current density of $10 \mathrm{~mA} / \mathrm{cm}^{2}$ was only $57 \mathrm{mV}$, indicating an excellent catalytic activity. The excellent catalytic activity was attributed to the rough, nanostructured catalyst morphology and high density of active sites provided by the amorphous structure. Sun et al. [36] reported an amorphous $\mathrm{MoS}_{2}$ porous thin film prepared by in-situ sulfurization of metallic Mo substrates as a high activity HER catalyst. Owing to the combination of the amorphous feature, porous structure and optimized thickness, this catalyst exhibited a small overpotential $(\sim 120 \mathrm{mV})$ and low Tafel slope $(\sim 41 \mathrm{mV} / \mathrm{dec})$ in HER. Min's group [37] prepared an amorphous $\mathrm{MoS}_{2}$ catalyst on $\mathrm{Au}$ by the atomic layer deposition method. This material exhibited a high turnover frequency of 3 $\mathrm{H}_{2} / \mathrm{s}$ at an overpotential of $0.215 \mathrm{~V}$, which was ascribed to the excellent electrical conductivity and a low activation energy.

Many strategies have been developed to maximize the catalytic activity of the amorphous molybdenum sulfide catalyst. First-row transition metals are often used as auxiliary elements to enhance the catalytic performance of molybdenum sulfide
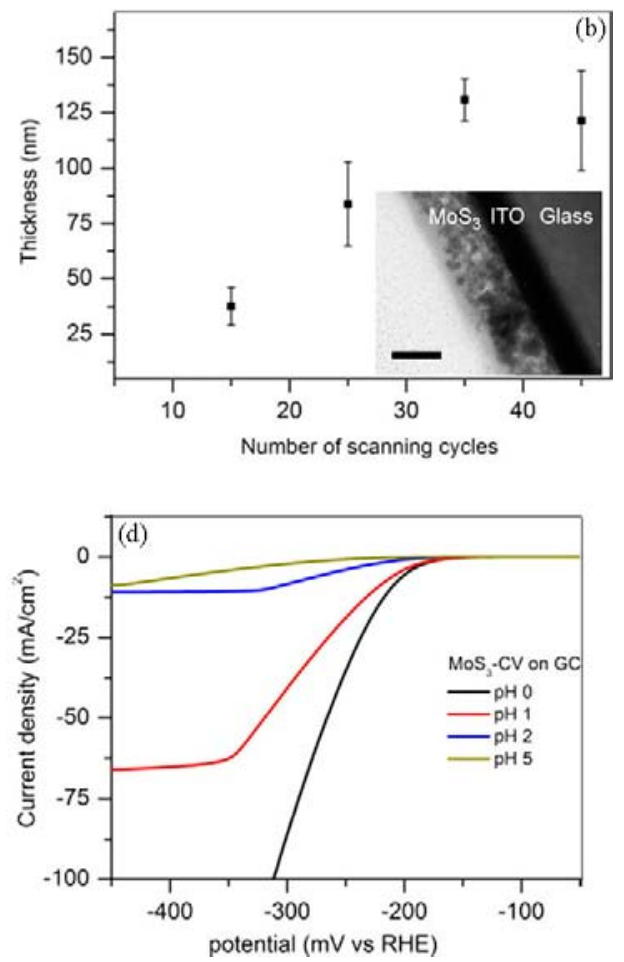

Fig. 3. (a) Cyclic curves for the electrodeposition of a molybdenum sulfide film (Inset: digital image of an amorphous molybdenum sulfide film on ITO during hydrogen evolution); (b) Thickness of $\mathrm{MoS}_{3}-\mathrm{CV}$ films as a function of the number of scanning cycles. (Inset: SEM image of a MoS $-\mathrm{CV}$ film on ITO. The scale bar corresponds to $50 \mathrm{~nm}$ ); (c) Polarization curves of $\mathrm{MoS}_{3}-\mathrm{CV}$ films with different thickness; (d) Polarization curves of a MoS ${ }_{3}-\mathrm{CV}$ film at different $\mathrm{pH}$. Reproduced with permission from Ref. [22]. 
[33], which is known as the hydrodesulfurization reaction. Hu 's group prepared ternary metal sulfide films, $M-\mathrm{MoS}_{3}(\mathrm{M}=\mathrm{Mn}$, $\mathrm{Fe}, \mathrm{Co}, \mathrm{Ni}, \mathrm{Cu}, \mathrm{Zn}$ ) and studied the effects of these elements on enhancing the performance of the catalyst in HER. They found that elements, including $\mathrm{Mn}, \mathrm{Cu}$ and $\mathrm{Zn}$, were not beneficial to enhance the catalytic activity, while Fe-, Co- and Ni-doped samples showed a significantly improved performance. In neutral conditions, the current density of the $\mathrm{Ni}-\mathrm{MoS}_{3}$ sample was ten times higher than that of pure $\mathrm{MoS}_{3}$ at an overpotential of 150 $\mathrm{mV}$. The enhancement with $\mathrm{Fe}$, $\mathrm{Co}$ and $\mathrm{Ni}$ ions could be explained by the promoted growth of the $\mathrm{MoS}_{3}$ films, resulting in a higher surface area and an increased catalyst loading. Wei's group [38] used niobium as the auxiliary element and prepared $\mathrm{Nb}$ added $\mathrm{MoS}_{x}$ catalysts for HER. With the assistance of $\mathrm{Nb}$, this material exhibited a Tefal slope of $50.5 \mathrm{mV} / \mathrm{dec}$ and an exchange current density of $1.5 \times 10^{-3} \mathrm{~mA} / \mathrm{cm}^{2}$ in $0.5 \mathrm{M} \mathrm{H}_{2} \mathrm{SO}_{4}$. Besides cation doping, anion-doped molybdenum sulfide has also been reported to show an excellent catalytic performance. Jin and co-authors [39] prepared a $\mathrm{MoS}_{x} \mathrm{Cl}_{y}$ material as an electrocatalyst for both electrochemical and photoelectrochemical hydrogen generation using a low-temperature chemical vapor deposition process. As a result of the synergistic effects of the high intrinsic activity, this material exhibited a superior catalytic activity. In addition, this material could be directly deposited on p-type silicon photocathodes to construct a highly efficient solar-driven photoelectrochemical hydrogen evolution device.

Loading amorphous molybdenum sulfides onto highly conductive materials (such as carbonaceous materials and porous metal substrates) is an efficient way to improve the electrical conductivity. Chang et al. [32] used a graphene-coated Ni foam as substrate to load $\mathrm{MoS}_{x}$ catalysts for HER. By decreasing the resistance, the catalyst exhibited an improved catalytic activity. Ge et al. [40] prepared an ultrathin amorphous molybdenum sulfide layer on nanoporous gold (NPG) substrate (Fig. 4). Owing to the high specific surface area and high conductivity of the nanoporous gold, this material exhibited a current density of $5.7 \mathrm{~mA} / \mathrm{cm}^{2}$ at $-0.2 \mathrm{~V}$ in $0.5 \mathrm{M} \mathrm{H}_{2} \mathrm{SO}_{4}$, which was more than six times higher than the same amorphous molybdenum sulfide loaded on a glassy carbon electrode (GCE). A substrate based on multiwalled carbon nanotubes is also commonly used for the deposition of amorphous molybdenum sulfide. Lin and co-workers [41] loaded amorphous molybdenum sulfide layer on the multiwalled carbon nanotube by a wet chemistry process. This material showed an overpotential of $0.13 \mathrm{~V}$ and a Tafel slope of $40 \mathrm{mV} / \mathrm{dec}$, which were attributed to the improved conductivity and the nature of amorphous molybdenum sulfide. Kim et al. [42] used a N-doped carbon nanotube as the substrate to further improve the catalytic performance. A small overpotential of $110 \mathrm{mV}$ was needed to obtain the current density of $10 \mathrm{~mA} / \mathrm{cm}^{2}$, which was reported as the highest HER activity of molybdenum sulfide-based catalyst at that time. Besides a carbon nanotube, Chorkendorf and co-authors [43] used piranha-etched carbon paper as the substrate. The porous carbon paper increased catalyst electrodeposition, leading to a better catalytic activity and stability.

\subsection{Other metal sulfide catalysts}

Besides molybdenum sulfide, amorphous cobalt sulfide was also recently discovered to be highly active for HER. Chang's group [44] used an electrochemical deposition method to fabricate an amorphous cobalt sulfide material on conductive substrates at room temperature. This material showed a high catalytic activity in neutral medium and is among the most active HER catalysts at $\mathrm{pH}=7$. It was also shown to be a durable catalyst for HER at $\mathrm{pH}=7$ with an operating stability of $40 \mathrm{~h}$. In addition, Yang's group [45] used ex-situ characterization to elucidate the structure and function evolution of an amorphous cobalt sulfide $\left(\operatorname{CoS}_{x}\right)$ catalyst. They observed that the cobalt in the $\operatorname{CoS}_{x}$ catalyst was surrounded by both sulfur and oxygen. They also used operando experiments to provide a molecular model in which cobalt was found to have an octahedral $\mathrm{CoS}^{2-}$-like state where the cobalt center is predominantly surrounded by a first shell of sulfur atoms, which, in turn, were preferentially exposed to the electrolyte compared with the bulk $\mathrm{CoS}_{2}$. They attributed the good catalytic performance to the exposure of a high density of catalytically active sulfur sites.
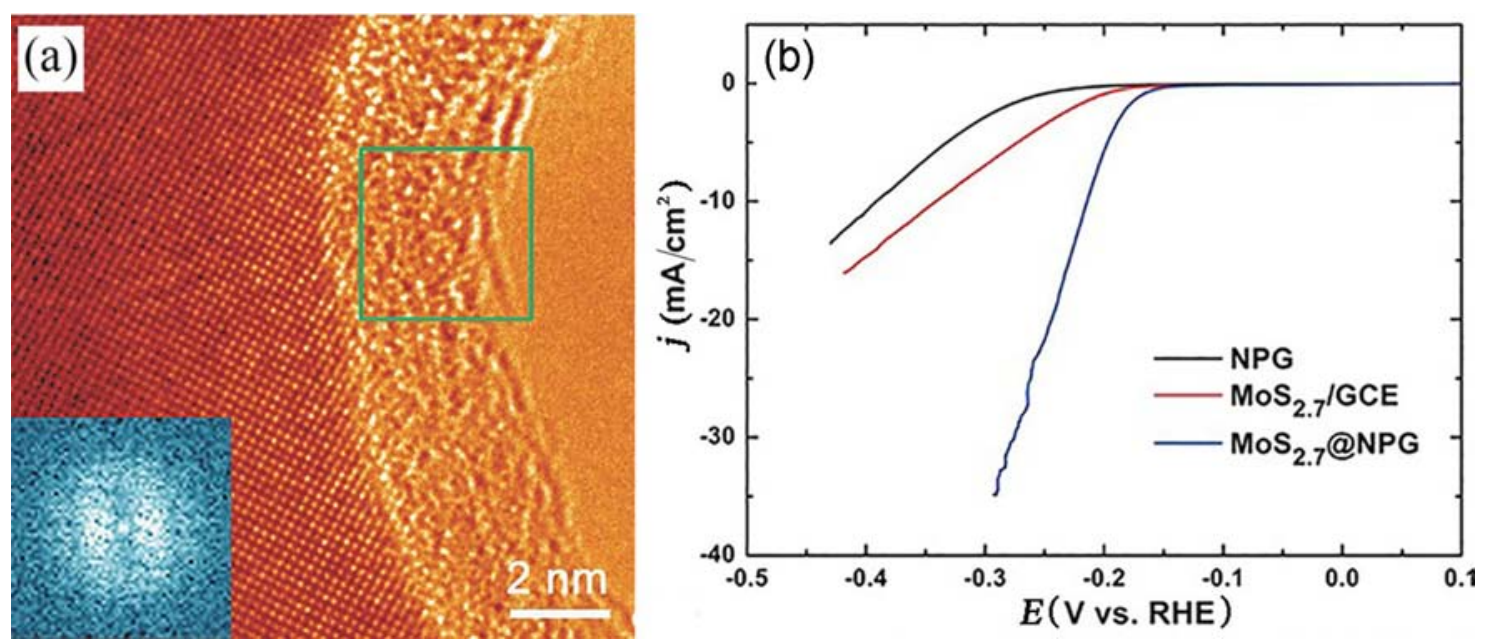

Fig. 4. (a) HRTEM micrograph of the NPG ligament and molybdenum sulfide layer (Inset is the FFT pattern from the labeled area); (b) HER polarization curves of NPG, $\mathrm{MoS}_{2.7}$ on a GCE, and $\mathrm{MoS}_{2.7}$ on NPG in $0.5 \mathrm{~mol} / \mathrm{L} \mathrm{H}_{2} \mathrm{SO}_{4}$. Reproduced with permission from Ref. [40]. 
In another study, Sun's group [46] loaded amorphous Ni-S films on fluorine-doped tin oxide (FTO) through potentiodynamic deposition followed by annealing. The Ni-S films showed catalytic activity over a wide range of $\mathrm{pH}$ values (0 to 14) and a superior stability in neutral water over $100 \mathrm{~h}$ with no deactivation.

Similar to the amorphous molybdenum sulfide catalysts, doping elements is a common way to enhance the catalytic activity of other sulfide materials for HER. Wu's group [47] prepared nickel and cobalt incorporated amorphous tungsten sulfides by a thermolytic process followed by annealing. The amorphous nickel tungsten sulfide delivered good catalytic activity and stability. The increased catalytic performance was attributed to the improved porous structure and chemical bonding states of $\mathrm{WS}_{3}$ by the introduction of $\mathrm{Ni}$ or $\mathrm{Co}$, resulting in an increase of the active sites. Yang et al. [48] reported on the synthesis of a nickel-oxide-coated cobalt manganese sulfide nanosheets array on carbon cloth (CoMn-S@NiO/CC) by the hydrothermal method. The CoMn-S@NiO/CC was transformed into the amorphous state by an electrochemical reduction process. It was found that the performance of CoMn-S@NiO/CC for HER was significantly improved. The enhanced catalytic activity was attributed to the amorphization of CoMn-S@NiO/CC, which led to the increase of defect-rich active sites and could significantly increase the internal surface area.

\subsection{Metal phosphide catalysts}

The application of metal phosphides as HER catalysts originates from the imitation of hydrogenase $[7,49]$. Different from metal sulfides, metal phosphides tend to form a more isotropic crystal structure, which offers more coordinatively unsaturated surface atoms, leading to an enhanced high intrinsic activity [50]. For example, Soriaga et al. [51] used cathodic deposition to prepare an amorphous cobalt phosphide film on a copper substrate in a boric acid solution of $\mathrm{Co}^{2+}$ and $\mathrm{H}_{2} \mathrm{PO}_{2}$. The as-deposited thin film was composed of metallic cobalt, phosphide, and amorphous-oxide. After the HER measurement, the Co:P ratio decreased from $20: 1$ to $1: 1$, indicating that the high-valence state of the Co species was removed under HER conditions. As a result of the in-situ film purification, the CoP film showed an overvoltage of $85 \mathrm{mV}$ at a current density of 10 $\mathrm{mA} / \mathrm{cm}^{2}$ and exhibited good stability after $24 \mathrm{~h}$ measurement. In another important study, Xiao et al. [52] reported a grain-mediated electroless deposition method for the preparation of amorphous tungsten-doped nickel phosphide microspheres on Ni foam. With the addition of the doped tungsten element, the catalyst exhibited a higher activity than the undoped nickel phosphide, leading to a high current density of 20 $\mathrm{mA} / \mathrm{cm}^{2}$ at the overpotential of $110 \mathrm{mV}$. Apart from nickel- and cobalt-based amorphous materials, Schaak's group [53,54] successfully prepared amorphous MoP and WP nanoparticles using the same method. They used $\mathrm{Mo}(\mathrm{CO})_{6}$ and $\mathrm{W}(\mathrm{CO})_{6}$ as metal element sources and trioctylphosphine as a phosphorus source. As shown in Fig. 5, the as-prepared nanoparticles were discrete and uniform, with the average diameter less than 5 $\mathrm{nm}$. Both the catalysts showed a much higher catalytic perfor-
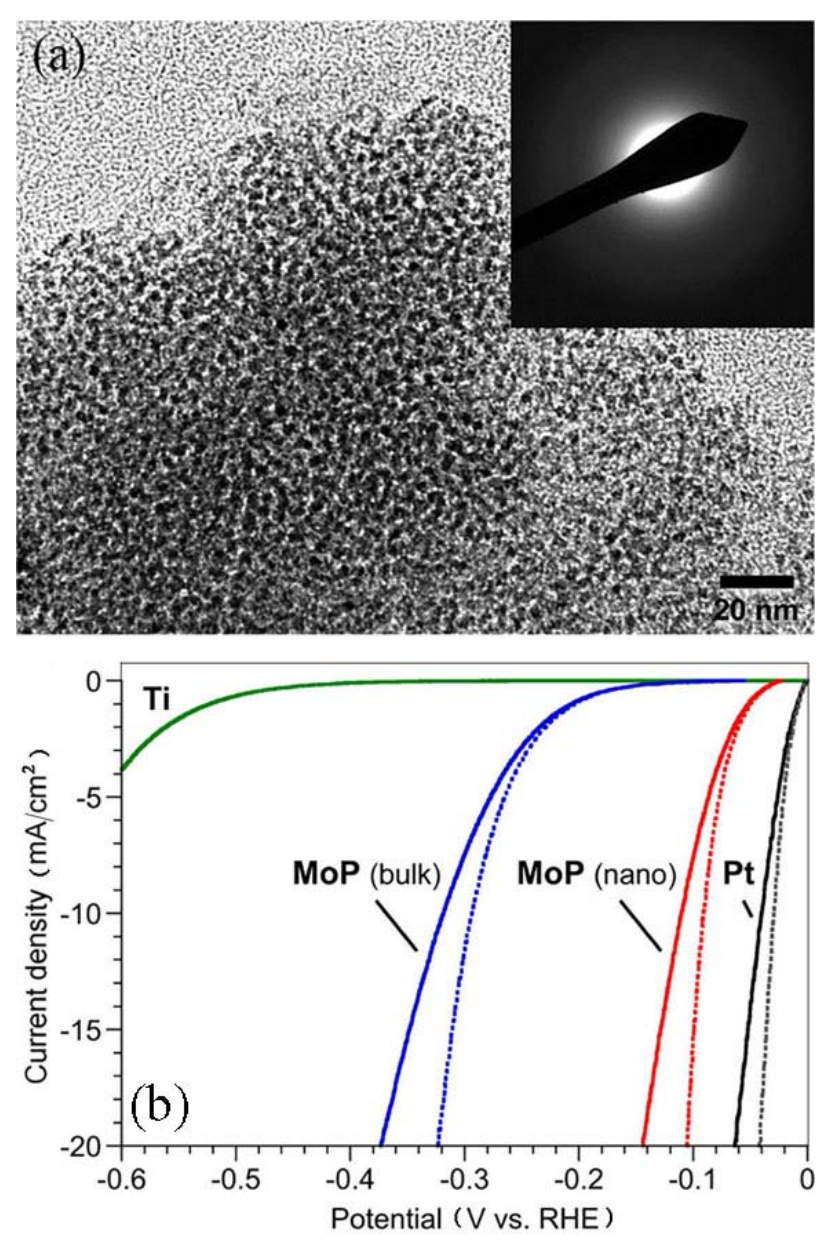

Fig. 5. (a) TEM image and corresponding SAED pattern of amorphous MoP nanoparticles heated to $450^{\circ} \mathrm{C}$; (b) Polarization curves of MoP/Ti, $\mathrm{MoP}, \mathrm{Pt}$ and Ti electrode in $0.50 \mathrm{~mol} / \mathrm{L} \mathrm{H}_{2} \mathrm{SO}_{4}$. The dashed lines correspond to the data after iR-correction. Reproduced with permission from Ref. [53].

mance than the bulk samples in acidic solution.

\subsection{Metal boride-based catalysts}

Metal borides possess similar physical properties to metal phosphides, such as high electrical conductivity and chemical stability, which make them suitable as HER catalysts. Patel et al. [55] reported amorphous cobalt-boride (Co-B)-based efficient and robust electrocatalysts for HER over a wide $\mathrm{pH}$ range $\mathrm{pH}=$ 4-9). In neutral solution, the amorphous Co-B nanoparticles (30-50 nm size) generated a low overpotential $(250 \mathrm{mV})$ at a current density of $10 \mathrm{~mA} / \mathrm{cm}^{2}$ with a Tafel slope of $75 \mathrm{mV} / \mathrm{dec}$. The good catalytic activity was attributed to the highly active Co surface sites created by electronic transfer from B to Co. Bai et al. [56] synthesized a nanostructured amorphous nickel boride (Ni-B) alloy by an electroless plating technique. This material exhibited a good catalytic efficiency and long-term stability over a broad $\mathrm{pH}$ range, which was comparable with the performance of Pt. A small overpotential of $132 \mathrm{mV}$ for the HER could be achieved at a current density of $20 \mathrm{~mA} / \mathrm{cm}^{2}$ at $\mathrm{pH}=0$ $\left(1 \mathrm{~mol} / \mathrm{L} \mathrm{HClO}_{4}\right)$. The high catalytic activity was caused by the 
amorphous structure and the moderate electron structure of $\mathrm{Ni}$-B. A catalytic material based on ternary Co-Ni-B was fabricated by Patel et al [57]. The Ni:Co ratio was adjusted over a wide range to identify the optimal catalytic activity. A current density of $10 \mathrm{~mA} / \mathrm{cm}^{2}$ was achieved at an overpotential of 170 $\mathrm{mV}$ at $\mathrm{pH}=7$ and $133 \mathrm{mV}$ at $\mathrm{pH}=14$. In their work, they explained the phenomenon by proposing that Ni promoted a higher electron density at Co active sites, which in turn facilitated an efficient reduction reaction to enhance the HER rate.

\subsection{Other types of HER catalysts}

Some amorphous metal selenides and metal oxides have also been reported to be used as HER catalysts. Lewis's group [58] reported an amorphous cobalt selenide film on Ti substrate by electrodeposition from an aqueous solution of $\mathrm{Co}\left(\mathrm{C}_{2} \mathrm{H}_{3} \mathrm{O}_{2}\right)_{2}$ and $\mathrm{SeO}_{2}$ under ambient conditions. The cobalt selenide films required an overpotential of $135 \mathrm{mV}$ to drive the HER at a current density of $10 \mathrm{~mA} / \mathrm{cm}^{2}$. Chen et al. [59] prepared a crystalline/amorphous core/shell $\mathrm{Co} / \mathrm{Co}_{3} \mathrm{O}_{4}$ catalyst through a hydrothermal process and hydrogenation. In $1 \mathrm{~mol} / \mathrm{L}$ $\mathrm{KOH}$, this catalyst showed a current density of $10 \mathrm{~mA} / \mathrm{cm}^{2}$ at an overpotential of $90 \mathrm{mV}$. The synergistic effect of the metallic core and the amorphous-oxide shell was regarded as the reason for the good catalytic performance, which resulted in both a good bulk conductivity and surface activity. Another core/shell structured catalytic material was prepared by the same group [60]. They used a similar procedure to prepare a crystalline/amorphous core/shell $\mathrm{Ni} / \mathrm{NiO}$ that also showed good catalytic activity. The electron transfer could be enhanced by a Ni core and the amorphous $\mathrm{NiO}$ shell could accelerate both the Volmer and Heyrovsky processes to drive the HER at low overpotentials.

\section{Electrocatalysts for OER}

Besides the importance of the binding energy of the reaction intermediates, there are other factors that also play critical roles in the OER process, such as specific surface area and electrical conductivity of the catalysts, current selectivity and wettability of the catalyst with electrolyte solution [5]. Owing to their poor corrosion resistance, carbides and nitrides might not be suitable as OER catalysts in acidic conditions, while some oxides may be stable enough and have good catalytic activities for OER in acidic solution [61-63]. However, most of the catalysts (such as hydroxides) reported so far are more stable in alkaline solution. Recently, earth-abundant semiconducting materials have gained much attention as OER catalysts. In contrast to metals, an electrical double layer is formed on the surface of the semiconductor material owing to the low electric conductivity. In general, arising from the accumulation of holes at the surface, the potential drop is negligible for a p-type semiconductor. However, for n-type semiconductors, the space charge layer at the interface leads to an additional barrier for charge carriers [5]. Therefore, p-type semiconductors or metal-like oxides should be more suitable as OER catalysts. Amorphous materials possess many advantages for OER. The disor- der in the atomic structure of the amorphous materials may improve electronic interactions and interatomic bonding, to facilitate hydroxyl ion bridging and terminal ligation of water, and thereby the catalytic activity $[64,65]$. Based on the above, amorphous OER catalysts are herein classified as oxides, hydroxides and other OER catalysts.

\subsection{Metal-oxide catalysts}

As mentioned above, p-type semiconductors, such as $\mathrm{Co}_{3} \mathrm{O}_{4}$, are widely used as OER catalysts. Zhao's group [66] fabricated amorphous $\mathrm{Co}_{3} \mathrm{O}_{4}$ nanoparticle/graphene composites $\left(\mathrm{Co}_{3} \mathrm{O}_{4} / \mathrm{GR}\right)$ through layer-by-layer assembly through electrophoretic deposition followed by chemical bath deposition. The catalytic activity of the as-prepared composites could be finely tuned by adjusting the number of bi-layers. The layered $\mathrm{Co}_{3} \mathrm{O}_{4} / \mathrm{GR}$ composite exhibited remarkable catalytic activity with a high Faradaic efficiency (95\%) in $0.1 \mathrm{~mol} / \mathrm{L} \mathrm{KOH}$. This highlighted the importance of the design and configuration of the composite catalyst. Switzer et al. [67] compared the OER catalytic activities of $\mathrm{CO}_{3} \mathrm{O}_{4}$ with different crystalline structures. They found that the amorphous sample showed better activity at a small current density $\left(40 \mathrm{~mA} / \mathrm{cm}^{2}\right)$ compared with that at a high current density. They attributed this crossover in the apparent activity to the higher resistance of the amorphous film caused by the poor adherence to the substrate.

Zaharieva et al. [65] reported an electrodeposited Mn oxide catalyst (MnCat) used at neutral $\mathrm{pH}$. By comparing the MnCat with an inactive manganese oxide material, they identified the high oxidation state and central structural motifs of $\mathrm{Mn}_{4} \mathrm{Cat}$ were crucial for catalytic activity. In addition, using X-ray absorption spectroscopy (XAS), they observed that the voltage-cycling protocol resulted in the formation of Mn(III) sites in the MnCat rather than the well-ordered and unreactive Mn(IV) in $\mathrm{MnO}_{2}$. The disordered atomic structure of the MnCat may facilitate the terminal ligation of water, thereby enhancing the catalytic activity. Lu et al. [68] prepared hydrogenated $\mathrm{TiO}_{2} / \mathrm{MnO}_{x}$ nanowires (NWs) on carbon cloth by the hydrothermal method followed by anodic electrodeposition. The thin amorphous $\mathrm{MnO}_{x}$ layer was regarded as the major potentially feasible part for OER. Owing to the synergistic effect between $\mathrm{TiO}_{2}$ and $\mathrm{MnO}_{x}$, the catalytic performance could be further improved. Chen et al. [69] fabricated 3D amorphous $\mathrm{FeO}_{x}$ and $\mathrm{FeSO}_{y}$ materials on a carbon fiber cloth by the hydrothermal method. After the electrochemical activation process, the 3D self-supported electrodes exhibited a superior OER activity compared with the previously reported iron oxide films.

The doping of auxiliary metal elements to fabricate multi-element oxides is a common way to enhance the OER activity. A bimetallic catalytic system containing $\mathrm{Ni}$ and $\mathrm{Fe}$ has been developed with the aim of improving the conductivity of nickel oxide even though the mechanism is still not clear. In the previous report, $\mathrm{Ni}$ was regarded to provide the active sites and the incorporation of $\mathrm{Fe}$ was used to induce some structural disorder [70]. The presence of Fe affected the redox properties of $\mathrm{Ni}$, making it harder to oxidize. This in turn reduced the average oxidation state and produced a Ni site that is more active 
for OER [71]. Recent studies also revealed that $\mathrm{Fe}^{3+}$ with a short $\mathrm{Fe}-\mathrm{O}$ bond distance in $\mathrm{Ni}_{1}{ }_{-} \mathrm{Fe}_{x} \mathrm{OOH}$ exhibits a lower overpotential than $\mathrm{Ni}^{3+}$ in $\mathrm{Ni}_{1}{ }_{x} \mathrm{Fe}_{x} \mathrm{OOH}$ and $\mathrm{NiOOH}$, indicating the Fe sites are the active sites for the OER [72]. Geng's group [73] synthesized amorphous mixed metal oxides through a controllable and continuous aerosol-spray-assisted approach. The content of metal elements could be precisely controlled to within $5 \pm 5 \%$. The $\mathrm{Fe}_{6} \mathrm{Ni}_{10} \mathrm{O}_{x}$ sample showed the best catalytic performance among the investigated $\mathrm{Fe}-\mathrm{Ni}-\mathrm{O}_{x}$ series with an overpotential of $0.286 \mathrm{~V}$ at a current density of $10 \mathrm{~mA} / \mathrm{cm}^{2}$ with a Tafel slope of $48 \mathrm{mV} / \mathrm{dec}$. Moreover, by comparing the materials after annealing, they confirmed that the amorphization was an efficient way to prepare homogenized materials. Zou et al. [74] reported a facile synthetic method for the preparation of amorphous nickel-iron oxide/carbon composite nanofibers through electrospinning synthesis and thermal conversion. The as-obtained material exhibited a comparable catalyst to $\mathrm{RuO}_{x}$. The efficient catalytic activity could be attributed to the amorphous phase structure of nickel-iron oxide, tunable $\mathrm{Ni} / \mathrm{Fe}$ atomic ratio, and strongly coupled interaction between the nickel-iron oxide and nanocarbon. Another amorphous $\mathrm{Fe} / \mathrm{Ni}$ composite oxide was fabricated by Geng's group [75]. In their work, a modified aerosol spray-assisted approach was obtained to obtain amorphous $\mathrm{Fe}-\mathrm{Ni}-\mathrm{O}_{x}$ nanoparticles by using iron/nickel acetylacetonates instead of inorganic salts. A small overpotential of $0.315 \mathrm{~V}$ was obtained at a current density of 50 $\mathrm{mA} / \mathrm{cm}^{2}$, and the Tafel slope was as low as $38 \mathrm{mV} / \mathrm{dec}$.

Besides the Ni-based catalyst, there have also been several reports on the Co-based catalysts. Tour and co-workers [76] used a microscope slide as the substrate and deposited an amorphous binary nickel and cobalt oxide layer on it by electrochemical method. The as-obtained catalytic layer exhibited good OER activity, which was rationalized by its high porous morphology and amorphous structure. Driess et al. [77] fabricated an amorphous self-supported cobalt-substituted zinc oxide (Co:ZnO) catalyst, which exhibited a good catalytic activity for OER. An amorphous layer was obtained when the $\mathrm{Co}: \mathrm{ZnO}$ precatalyst was electrodeposited onto fluorine-doped tin oxide electrodes. The Co-rich hydroxide-oxidize electrocatalyst performed well at low overpotentials and demonstrated good stability. Ma et al. [78] designed nanoporous Co-Fe coupled nitrogen-enriched carbon nanosheets $\left(\mathrm{Co}_{y} \mathrm{Fe}_{10-y} \mathrm{O}_{x} / \mathrm{NPC}\right)$ by a hydrothermal process followed by annealing. They found that the $\mathrm{Co}_{3} \mathrm{Fe}_{7} \mathrm{O}_{x} / \mathrm{NPC}$ showed the highest activity among the samples investigated. An overpotential of $328 \mathrm{mV}$ was needed at a stable current density of $10 \mathrm{~mA} / \mathrm{cm}^{2}$ with a small Tafel slope of $31.4 \mathrm{mV} / \mathrm{dec}$ in $1.0 \mathrm{~mol} / \mathrm{L} \mathrm{KOH}$ solution. Driess et al. [79] used a solvothermal route to fabricate amorphous and crystalline cobalt iron oxides by controlling the crystallinity of the materials by changing the solvent and reaction time. Notably, the amorphous sample exhibited a superior catalytic activity over that of the crystalline sample towards photochemical and electrochemical water oxidation under oxygen reduction conditions.

Amorphous ternary and multi-metal element oxides have also been reported to exhibit enhanced catalytic performances. Trudel et al. [80] developed a general method for fabricating amorphous oxides with compositions that can be accurately controlled based on the photodecomposition of organometallic precursors. Compared with the traditional electrodeposition techniques, the photochemical metal-organic deposition could be widely used for metal elements and be more feasible for the fabrication of materials containing multiple metals. As shown in Fig. 6, a catalyst based on $\alpha-\mathrm{Fe}_{100-y-z} \mathrm{Co}_{y} \mathrm{Ni}_{z} \mathrm{O}_{x}$ was synthesized and the thickness of the catalyst layer was $\sim 200 \mathrm{~nm}$. Benefiting from the synergistic effect of $\mathrm{Fe}, \mathrm{Co}$ and $\mathrm{Ni}$, the catalytic activity of $\alpha-\mathrm{Fe}_{100-y-z} \mathrm{Co}_{y} \mathrm{Ni}_{z} \mathrm{O}_{x}$ was comparable to the noble metal-oxide catalysts. By exploiting the advantages of photochemical metal-organic deposition, they further mapped the performance of amorphous ternary $\mathrm{Ni}-\mathrm{Fe}-\mathrm{Co}$ and $\mathrm{Ni}-\mathrm{Fe}-\mathrm{Al}$ oxides to determine how the composition affected the activity of the ternary amorphous metal-oxide catalysts $[81,82]$. It was found that small concentrations of iron and aluminum produced a significant improvement in the Tafel slopes and cobalt or nickel was critical in lowering the voltage at which catalysis started to occur, especially for the Ni-Fe-Al system. A series of materials based on the Ni-Fe-Al system delivered strikingly low Tafel slopes of $11-27 \mathrm{mV} / \mathrm{dec}$, which were among the best values reported at that time. Recently, the same group presented an amorphous quaternary Ba-Sr-Co-Fe oxide (a-BSCF) fabricated by a similar method [83]. The a-BSCF demonstrated high catalytic activity with an overpotential of $252 \mathrm{mV}$ at a current density of 1 $\mathrm{mA} / \mathrm{cm}^{2}$. An in-situ grown Fe-Co-Ni ternary alloy amorphous-oxide was fabricated by Zhao et al. [84] through anodization followed by low-temperature annealing. This material showed superior electrocatalytic activity with an overpotential of only $170 \mathrm{mV}$ at a current density of $5 \mathrm{~mA} / \mathrm{cm}^{2}$.

\subsection{Metal hydroxide-based electrocatalysts}

Recently, hydroxides, as a class of layered material, has attracted interest owing to their great affinity to aqueous electrolytes and large surface area with more accessible active sites [85]. Yang et al. [86] demonstrated an electrochemical method to fabricate amorphous metal hydroxides. The as-synthesized $\mathrm{Co}(\mathrm{OH})_{2}$ electrode exhibited an overpotential of $0.38 \mathrm{~V}$ at a current density of $10 \mathrm{~mA} / \mathrm{cm}^{2}$ and a Tafel slope of $68 \mathrm{mV} / \mathrm{dec}$. The amorphous $\mathrm{Ni}(\mathrm{OH})_{2}$ afforded a better performance with a current density of $10 \mathrm{~mA} / \mathrm{cm}^{2}$ at an overpotential of $0.344 \mathrm{~V}$ and a Tafel slope of $46 \mathrm{mV} / \mathrm{dec}[87,88]$.

Similar to the metal-oxide materials, the NiFe hydroxides have attracted considerable attention. As demonstrated by Zhao et al. [89], amorphous Ni-Fe hydroxide nanosheets were prepared using a potentiostatic method and exhibited excellent catalytic activity. In $10 \mathrm{~mol} / \mathrm{L} \mathrm{KOH}$ solution, Ni-Fe hydroxide showed a current density of $500 \mathrm{~mA} / \mathrm{cm}^{2}$ at $240 \mathrm{mV}$ overpotential arising from the high surface area and fast electron transport properties. Another NiFe hydroxide was fabricated by Yang's group [90]. They used an electrochemical technique to prepare a catalytic nanostructure with tunable $\mathrm{Ni} / \mathrm{Fe}$ ratio. At a current density of $10 \mathrm{~mA} / \mathrm{cm}^{2}$, the overpotential was a mere $0.296 \mathrm{~V}$ and the small Tafel slope was $58 \mathrm{mV} / \mathrm{dec}$. Tang et al. [91] synthesized Ni-Co amorphous double hydroxide hollow structures with a tunable $\mathrm{Ni} / \mathrm{Co}$ molar ratio through a templat- 

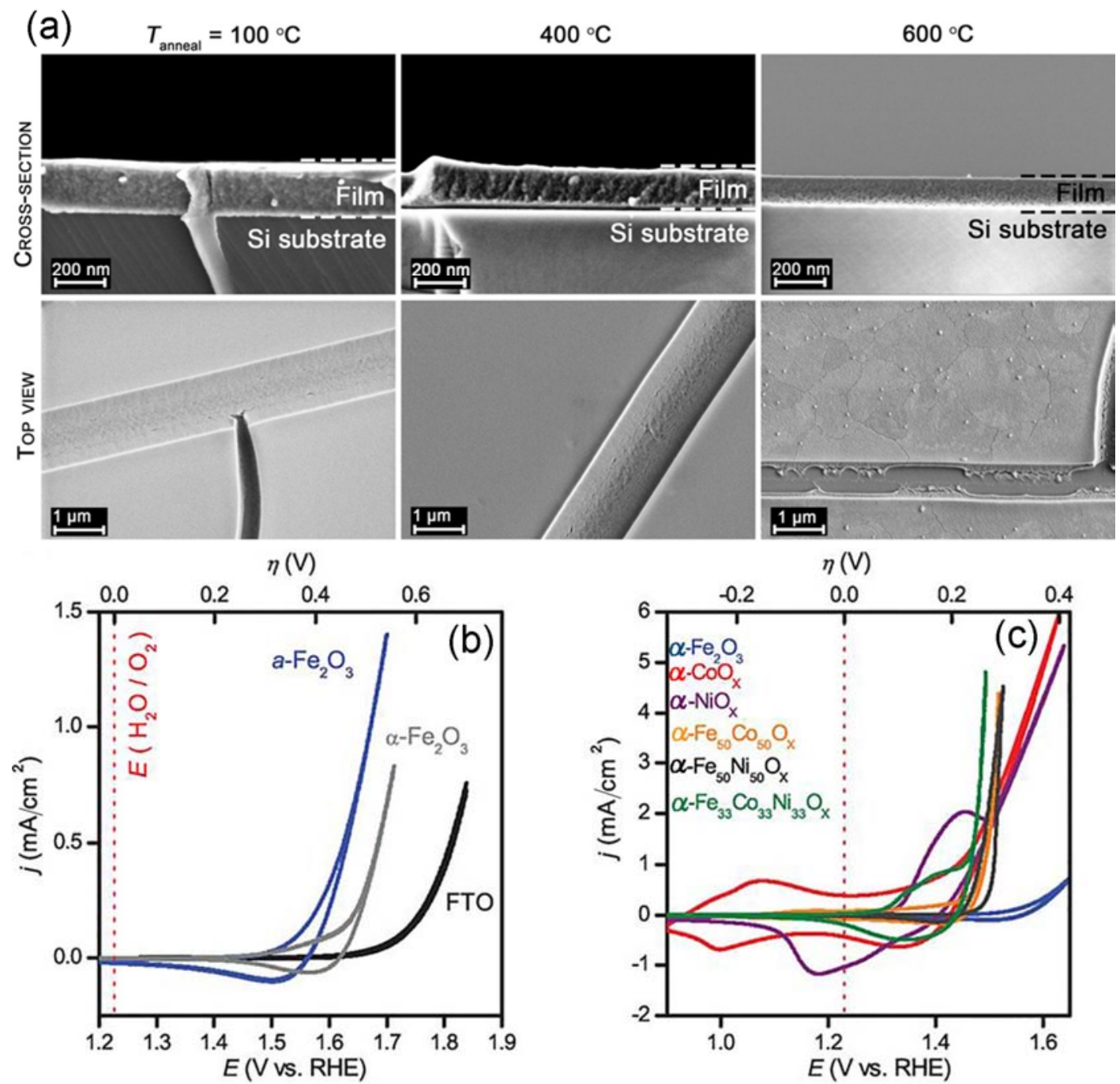

Fig. 6. (a) SEM cross-section and top-view images of $\alpha$ - $\mathrm{Fe}_{2} \mathrm{O}_{3}$ films prepared by photochemical metal-organic deposition, followed by annealing at 100 ${ }^{\circ} \mathrm{C}, 400{ }^{\circ} \mathrm{C}$, or $600{ }^{\circ} \mathrm{C}$; (b) Cyclic voltammograms for different types of $\mathrm{Fe}_{2} \mathrm{O}_{3}$, indicating that the amorphous $\mathrm{Fe}_{2} \mathrm{O}_{3}$ exhibited a higher catalytic activity; (c) Cyclic voltammograms of $\alpha-\mathrm{Fe}_{2} \mathrm{O}_{3}, \alpha-\mathrm{Fe}_{50} \mathrm{Ni}_{50} \mathrm{O}_{x}, \alpha-\mathrm{Fe}_{50} \mathrm{Co}_{50} \mathrm{O}_{x}$, and $\alpha-\mathrm{Fe}_{33} \mathrm{Co}_{33} \mathrm{Ni}_{33} \mathrm{O}_{x}$ films, demonstrating the synergistic effect between the $\mathrm{Ni}$, $\mathrm{Fe}$ and Co elements. Reproduced with permission from Ref. [80].

ing method. The amorphous $\mathrm{NiCo}_{2.7}(\mathrm{OH})_{x}$ nanocages demonstrated a high catalytic activity and excellent stability. According to the density functional theory simulations, the component-dependent electrocatalytic activities were correlated to the binding energies of the oxygen radical on the diverse hydroxides. Hu's group [92] reported ultrathin nanoplates composed of Co-Mn layered double hydroxide (CoMn LDH) with high activity and stability, which was fabricated by a one-pot co-precipitation method. This material showed quite a high turnover frequency, which was more than 20 times higher than that of individual Co and Mn oxides and hydroxides, and nine times higher than the precious $\mathrm{IrO}_{2}$ catalyst. The enhanced catalytic activity could be summarized by the formation of amorphous layers at the surface and possibly the accumulation of active $\mathrm{Co}(\mathrm{IV})$ species in the amorphous layers.

Vojvodic et al. [93] reported the synthesis of an amorphous Co-Fe-W oxy-hydroxide through the sol-gel method. The material showed an excellent catalytic performance (Fig. 7). These gelled FeCoW oxy-hydroxide exhibited the lowest overpotential
$(191 \mathrm{mV})$ reported at a current density of $10 \mathrm{~mA} / \mathrm{cm}^{2}$ in alkaline electrolyte and there was no evidence of activity degradation after a 500-hours stability test. Density functional theory suggested the adsorption energies of OER intermediates could be adjusted to a near-optimal value by adding non-3d high-valence metal elements into the CoFe atomic structure. A synergistic interplay among $\mathrm{W}, \mathrm{Fe}$ and Co was detected by X-ray absorption. A computational study showed a favorable local coordination environment and electronic structure was formed in the material, which reduced the energy barrier for OER.

\subsection{Other catalysts}

Nocera's group [94] has made a great contribution to fabricating amorphous metal phosphate and borate materials for OER. They first reported an electrodeposition method to fabricate a phosphate based catalyst on an indium tin oxide electrode using a phosphate-buffered water solution containing 

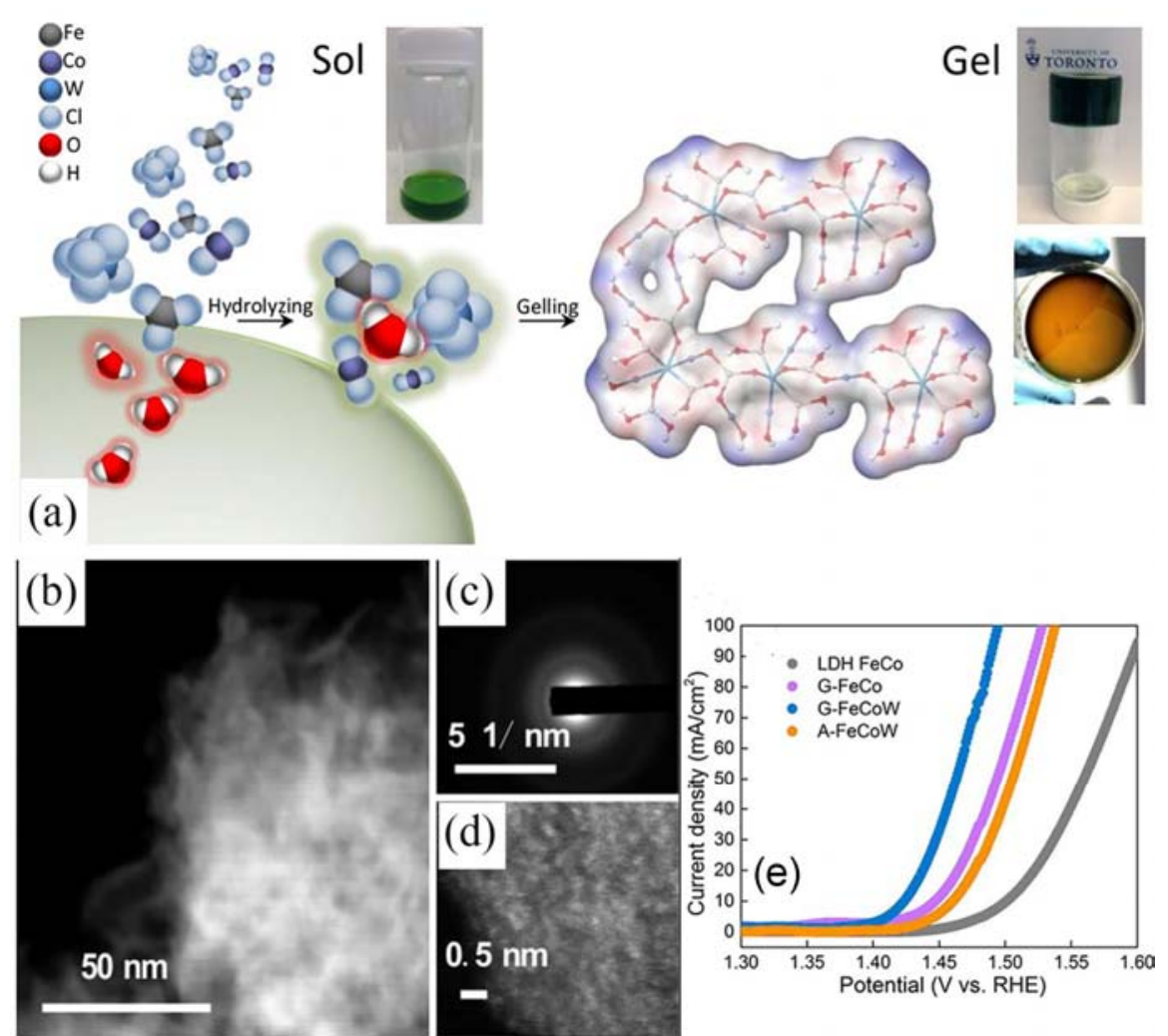

Fig. 7. (a) Schematic illustration of the sol-gel preparation process; (b) High-angle-annular-dark-field (HAADF) STEM image; (c) Selected area electron diffraction pattern and (d) Atomic-resolution HAADF-STEM image of the nanoporous structure of G-FeCoW; (e) Polarization curves of different catalysts loaded on gold-plated Ni foam without iR-correction. Reproduced with permission from Ref. [93].

cobalt (II) ions. As shown in Fig. 8, after electrodeposition, this material exhibited a low onset potential for OER in neutral solution. The $\mathrm{pH}$ dependence of the catalytic activity implied the hydrogen phosphate ion was the proton acceptor in the oxygen-producing reaction. In addition, this catalyst layer was formed in-situ during the oxygen-producing process, which made it possible for this material to be a self-repairing catalyst. Another type of nickel-borate was synthesized by this group from dilute $\mathrm{Ni}^{2+}$ solutions in borate electrolyte at $\mathrm{pH}=9.2$ [95]. The as-prepared catalyst layer with precise thickness control at modest overpotential provided an alternative to the Co-based catalyst mentioned above. The same group [96] also used a similar method to improve the catalytic performance of cobalt-based borate electrolyte. The borate material achieved a current density of $100 \mathrm{~mA} / \mathrm{cm}^{2}$ at $363 \mathrm{mV}$ overpotential in natural water. Inspired by Nocera et al., Dau et al. [97] deposited cobalt phosphate catalysts on inert electrodes to study the OER mechanism. According to the X-ray spectroscopy studies and electrochemical measurements, they proposed that both surface catalysis and bulk-volume catalysis need to be considered when striving for a complete picture of heterogeneous water oxidation, including the electrolyte-exposed "outer surface", hydrated amorphous volume phase and kinetics of restructuring upon operation.

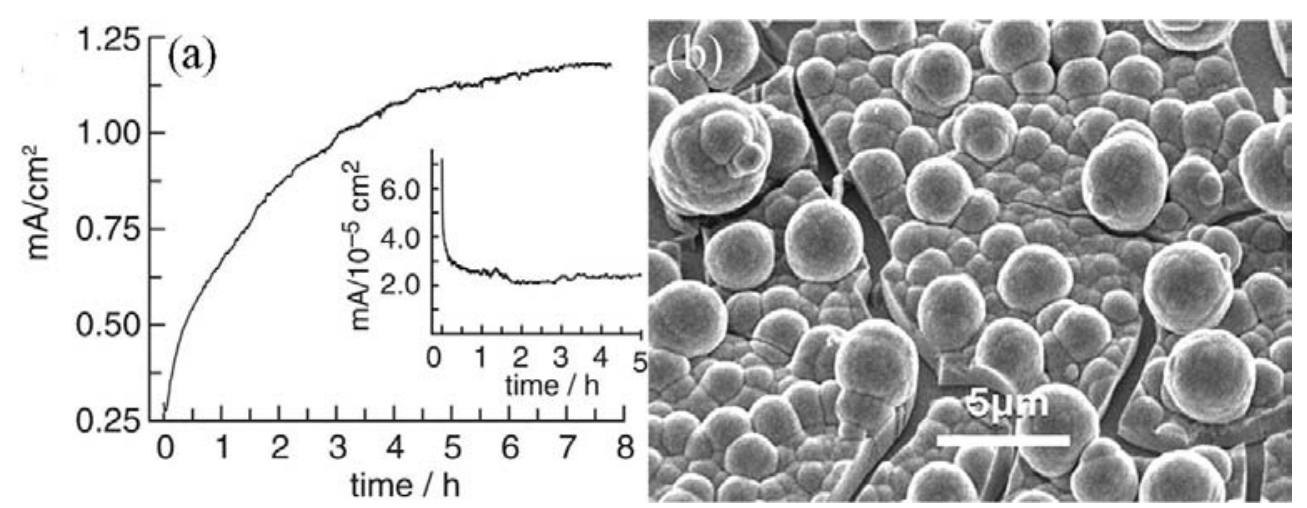

Fig. 8. (a) Potentiostatic curve for bulk electrolysis at $1.29 \mathrm{~V}$ (versus NHE) in $0.1 \mathrm{~mol} / \mathrm{L} \mathrm{KPi}$ electrolyte at $\mathrm{pH} 7.0$ containing $0.5 \mathrm{mmol} / \mathrm{L} \mathrm{Co}{ }^{2+}($ Inset is the profile without $\mathrm{Co}^{2+}$ ); (b) SEM image of the electrodeposited catalyst at $30 \mathrm{C} / \mathrm{cm}^{2}$ in $0.1 \mathrm{~mol} / \mathrm{L} \mathrm{KPi}$ containing $0.5 \mathrm{mmol} / \mathrm{L} \mathrm{Co}^{2+}$. Reproduced with permission from Ref. [94]. 
Besides electrodeposition, chemical methods have also been widely used to prepare amorphous metal borate and carbonate. Wu et al. [98] synthesized a cobalt-based borate (Co-B) ultrathin nanosheet/graphene hybrid material using a room temperature chemical synthesis method. Benefiting from the large amount of exposure of active sites and enhanced electron transfer, as well as the synergetic coupling effect between Co and $\mathrm{B}$, the as-prepared material showed a high catalytic activity with current density of $10 \mathrm{~mA} / \mathrm{cm}^{2}$ at an overpotential of 290 $\mathrm{mV}$ in an alkaline medium. Zhou et al. [99] prepared amorphous nickel carbonate particles for OER by an evaporation-induced precipitation method. The amorphous structure could be easily controlled by the $\mathrm{H}_{2} \mathrm{O} / \mathrm{Ni}$ ratio in the precursor mixture. The best sample in their case showed a current density of $55.1 \mathrm{~A} / \mathrm{g}$ at an overpotential of $0.35 \mathrm{~V}$ with a Tafel slope of $60 \mathrm{mV} / \mathrm{dec}$.

\section{Bifunctional catalysts}

Plenty of materials with good catalytic activities for either HER or OER have been applied for water splitting. However, the development of a bifunctional catalyst for simultaneous generation of $\mathrm{H}_{2}$ and $\mathrm{O}_{2}$ remains a big challenge to improve the overall efficiency of water electrolysis [100]. So far, there have only been a few reports about amorphous bifunctional materials for the electrolysis of water splitting. To the best of our knowledge, most of the amorphous bifunctional materials are unitary metals. There is still great potential for the development of multi-element and new types of amorphous bifunctional materials.

$\mathrm{Du}$ et al. [101] prepared a nickel-based thin film $\left(\mathrm{NiO}_{x}\right)$ on multiwalled carbon nanotubes (MWCNTs) by the electrodeposition method. By using MWCNTs, the $\mathrm{NiO}_{x}$ layer under HER condition $\left(\mathrm{H}_{2}-\mathrm{NiO}_{x}\right)$ showed a good catalytic activity for HER in a near-neutral aqueous solution. For OER, the amorphous $\mathrm{H}_{2}-\mathrm{NiO}_{x}$ film transformed into another amorphous material $\left(\mathrm{O}_{2}-\mathrm{NiO}_{x}\right)$ and exhibited a better performance than the $\mathrm{H}_{2}-\mathrm{NiO}_{x}$. Another amorphous $\mathrm{NiO}_{x}$ layer, prepared by similar electrodeposition method, was reported by Wu's group [102]. The catalyst mediated HER and OER in a near-neutral aqueous buffer at a low overpotential. Both $\mathrm{NiO}_{x}$ catalysts mentioned above demonstrated good stability and reversible stability. Sun et al. [103] reported a chemical deposition method to fabricate $\mathrm{Ni}$-B nanoparticles loaded on Ni foam. This material exhibited a cell voltage of $1.69 \mathrm{~V}$ at a current density of $15 \mathrm{~mA} / \mathrm{cm}^{2}$ in the two-electrode system.

Yoo et al. [104] reported a carbon-supported cobalt phosphide (CoP) material as a bifunctional material in alkaline solution (as shown in Fig. 9). The efficient HER catalyst experienced
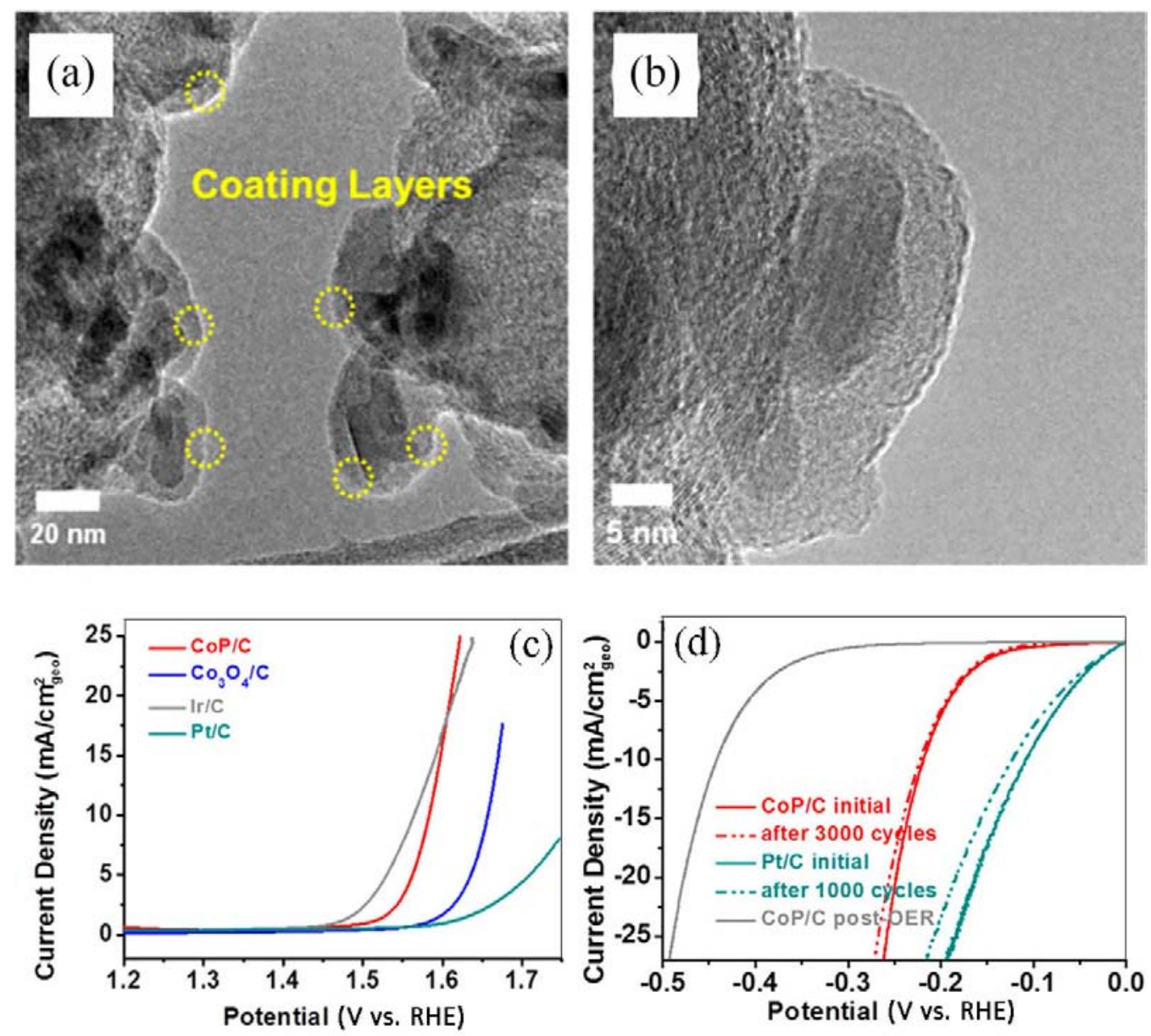

Fig. 9. (a) TEM image and (b) HRTEM image of the as-prepared CoP/C. (c, d) Polarization curves of the as-prepared catalysts for both HER and OER in $0.1 \mathrm{~mol} / \mathrm{L} \mathrm{KOH}$, indicating excellent bifunctional catalytic performance. Reproduced with permission from Ref. [104]. 
a morphology change from metamorphosis to nanoweb-like dispersed morphologies upon anodic potential, which produced efficient and robust catalytic environments for OER. Under an anodic potential, a discrete cobalt-oxo/hydroxo molecular unit was generated within a phosphate-enriched amorphous network, which benefited the OER catalytic performance. Luo et al. [105] synthesized an amorphous CoSe film on Ti mesh through an electrodeposition method. This material showed good catalytic performance for both HER and OER. Overpotentials of 292 and $121 \mathrm{mV}$ were obtained for OER and HER, respectively, leading to an electrolysis window of $1.65 \mathrm{~V}$ in the two-electrode system at the current density of 10 $\mathrm{mA} / \mathrm{cm}^{2}$. A $\mathrm{CoO} / \mathrm{MoO}_{x}$ crystalline/amorphous structure converted from $\mathrm{CoMoO}_{4}$ by hydrogenation was reported by Chen et al [106]. The catalyst showed small onset overpotentials of 40 and $230 \mathrm{mV}$ for the HER and OER in $1.0 \mathrm{~mol} / \mathrm{L} \mathrm{KOH}$, respectively. It also exhibited a good overall water splitting activity and robust stability, which could be attributed to the large defect-rich interface between $\mathrm{CoO}$ and $\mathrm{MoO}_{x}$, along with the amorphous nature of $\mathrm{MoO}_{x}$.

\section{Conclusions and outlook}

The technology of the electrolysis of water offers a promising way to store electric energy. The development of efficient and low-cost catalysts for both HER and OER of water electrolysis is critical to promote the commercial application of this technology in practice. To date, although many materials have been developed as HER and OER catalysts, there is still much room to improve the performance of catalysts and reduce the cost through material engineering.

In particular, amorphous materials using earth-abundant elements have demonstrated the capability, as alternative noble metal free catalysts, to deliver high-energy efficiency in water electrolysis. Compared with the crystalline materials, the amorphous materials have a more flexible composition, more disordered atomic structure and a greater number of active sites. However, the conductivity and chemical stability of the amorphous materials limit their performance. In addition, the catalytic mechanism of amorphous materials is still not clear. Moreover, compared with noble metal-based catalysts, the long-term stability of the amorphous catalytic material is still unsatisfactory. Amorphous materials always suffer from chemical and electrochemical corrosion under the HER and OER processes. Furthermore, the amorphous catalyst coating normally suffers poor interface connection especially in the large area electrode. At a high anodic overpotential, side reactions, like oxidation of catalyst and substrate, can hinder the improvement of the energy usage rate. Moreover, efficient HER and OER generation normally takes place in either acidic or alkaline environments, respectively. Bifunctional catalysts provide a feasible route to realize overall water electrolysis for practical application. In addition, fabrication of bifunctional materials will reduce the cost of production and replacement. However, development of a bifunctional catalyst for an overall water electrolysis system, which involves both HER an OER, remains a substantial challenge. The catalytic activities of the bifunctional materials are still not comparable with the single HER and OER catalysts.

To overcome these drawbacks and realize a wide range of commercial uses for sustainable hydrogen production, the following advancements are proposed for further improvement. First, a good understanding of the fundamental mechanism of water electrolysis is essential to fabricate high-performance catalysts. Even though molybdenum sulfides have been widely studied and the catalytic mechanism of this type of material is relatively clear, the catalytic mechanisms for most of the other materials are still under debate. In particular, there is still a lack of depth in the mechanistic investigation on amorphous catalysts on an atomic level. Owing to its disordered atomic structure, it is hard to obtain structural information of the amorphous material using normal characterization methods (such as X-ray diffraction). Tools, like XAS, are necessary for providing more precise structural information such as local coordination geometries and bond distances of amorphous catalysts. Second, the activity of water electrolysis catalysts needs to be further improved. An ideal catalyst for water electrolysis should have a high efficiency, good stability, low cost and scalability. Currently, transition metal phosphides with excellent catalytic activities seem to be promising catalysts for water electrolysis. However, although amorphous film deposition can be sensitive to the voltage protocol, it is hard to keep the balance between the deposition potentials and crystallization potential for each metal elements to prepare amorphous multiple metal catalysts. Finding new methods to fabricate amorphous phosphides containing multi-elements might solve the problem in the future. The development of bifunctional catalysts for the electrolysis of water is very attractive for highly efficient water electrolysis.

\section{Acknowledgments}

W. C. Xu acknowledges the financial support from Chinese Scholarship Council (CSC) and H. X. Wang thanks the support from Australian Research Council (ARC) Future Fellowship scheme.

\section{References}

[1] H. Ibrahim, A. Ilinca, J. Perron, Renew. Sust. Energ. Rev., 2008, 12, 1221-1250.

[2] H. W. Wu, Appl. Energy, 2016, 165, 81-106.

[3] S. Trasatti, J. Electroanal. Chem., 1999, 476, 90-91.

[4] X. M. Li, X. G. Hao, A. Abudula, G. Q. Guan, J. Mater. Chem. A, 2016, 4, 11973-12000.

[5] E. Fabbri, A. Habereder, K. Waltar, R. Kotz, T. J. Schmidt, Catal. Sci. Technol., 2014, 4, 3800-3821.

[6] F. M. Wang, T. A. Shifa, X. Y. Zhan, Y. Huang, K. L. Liu, Z. Z. Cheng, C. Jiang, J. He, Nanoscale, 2015, 7, 19764-19788.

[7] X. X. Zou, Y. Zhang, Chem. Soc. Rev., 2015, 44, 5148-5180.

[8] F. Safizadeh, E. Ghali, G. Houlachi, Int. J. Hydrogen Energy, 2015, 40, 256-274.

[9] M. Zeng, Y. G. Li, J. Mater. Chem. A, 2015, 3, 14942-14962.

[10] T. R. Cook, D. K. Dogutan, S. Y. Reece, Y. Surendranath, T. S. Teets, D. G. Nocera, Chem. Rev., 2010, 110, 6474-6502. 


\section{Graphical Abstract}

Chin. J. Catal., 2017, 38: 991-1005 doi: 10.1016/S1872-2067(17)62810-9

\section{Earth-abundant amorphous catalysts for electrolysis of water}

Wence Xu, Hongxia Wang* Queensland University of Technology, Australia; Tianjin University, China
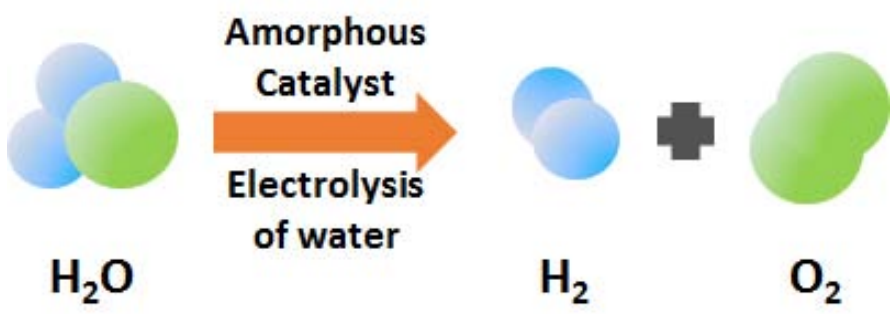

This minireview summarizes the recent progress of amorphous catalysts based on earth-abundant elements for the electrolysis of water. The advantages, drawbacks and the perspectives in the future are also discussed.

[11] H. L. Yu, X. B. Yu, Y. J. Chen, S. Zhang, P. Gao, C. Y. Li, Nanoscale, 2015, 7, 8731-8738.

[12] X. B. Yu, S. Zhang, C. Y. Li, C. L. Zhu, Y. J. Chen, P. Gao, L. H. Qi, X. T. Zhang, Nanoscale, 2016, 8, 10902-10907.

[13] K. Zhang, Y. Zhao, D. Y. Fu, Y. J. Chen, J. Mater. Chem. A, 2015, 3, 5783-5788.

[14] S. Zhang, X. B. Yu, F. Yan, C. Y. Li, X. T. Zhang, Y. J. Chen, J. Mater. Chem. A, 2016, 4, 12046-12053.

[15] Z. X. Yin, Y. J. Chen, Y. Zhao, C. Y. Li, C. Zhu, X. T. Zhang, J. Mater. Chem. A, 2015, 3, 22750-22758.

[16] L. Trotochaud, S. L. Young, J. K. Ranney, S. W. Boettcher, J. Am. Chem. Soc., 2014, 136, 6744-6753.

[17] J. F. Xie, Y. Xie, ChemCatChem, 2015, 7, 2568-2580.

[18] T. Reier, I. Weidinger, P. Hildebrandt, R. Kraehnert, P. Strasser, ECS Trans., 2013, 58, 39-51.

[19] D. Merki, S. Fierro, H. Vrubel, X. L. Hu, Chem. Sci., 2011, 2, 1262-1267.

[20] J. D. Benck, Z. B. Chen, L. Y. Kuritzky, A. J. Forman, T. F. Jaramillo, Acs Catal., 2012, 2, 1916-1923.

[21] Q. Lu, G. S. Hutchings, R. V. Forest, J. Rosen, B. T. Yonemoto, F. Jiao, W. T. Yu, G. G. Chen, Y. Zhou, J. Q. Xiao, R. Z. Tao, H. M. Zheng, Z. Y. Cao, Nat. Commun., 2015, 6, 6567.

[22] H. Dau, C. Limberg, T. Reier, M. Risch, S. Roggan, P. Strasser, Chem CatChem, 2010, 2, 724-761.

[23] W. T. Hong, M. Risch, K. A. Stoerzinger, A. Grimaud, J. Suntivich, Y. Shao-Horn, Energy Environ. Sci., 2015, 8, 1404-1427.

[24] I. C. Man, H. Y. Su, F. Calle-Vallejo, H. A. Hansen, J. I. Martinez, N. G. Inoglu, J. Kitchin, T. F. Jaramillo, J. K. Norskov, J. Rossmeisl, ChemCatChem, 2011, 3, 1159-1165.

[25] J. Greeley, T. F. Jaramillo, J. Bonde, I. B. Chorkendorff, J. K. Norskov, Nat. Mater., 2006, 5, 909-913.

[26] L. Margulis, G. Salitra, R. Tenne, M. Talianker, Nature, 1993, 365, 113-114.

[27] T. Weber, J. C. Muijsers, J. W. Niemantsverdriet, J. Phys. Chem., 1995, 99, 9194-9200.

[28] C. G. Morales-Guio, X. L. Hu, Acc. Chem. Res., 2014, 47, 2671-2681.

[29] C. G. Morales-Guio, L. A. Stern, X. L. Hu, Chem. Soc. Rev., 2014, 43, 6555-6569.

[30] A. J. Jacobson, R. R. Chianelli, S. M. Rich, M. S. Whittingham, Mater. Res. Bull., 1979, 14, 1437-1448.

[31] J. D. Benck, T. R. Hellstern, J. Kibsgaard, P. Chakthranont, T. F. Jaramillo, ACS Catal., 2014, 4, 3957-3971.
[32] Y. H. Chang, C. T. Lin, T. Y. Chen, C. L. Hsu, Y. H. Lee, W. J. Zhang, K. H. Wei, L. J. Li, Adv. Mater, 2013, 25, 756-760.

[33] D. Merki, H. Vrubel, L. Rovelli, S. Fierro, X. L. Hu, Chem. Sci., 2012, 3, 2515-2525.

[34] H. Vrubel, D. Merki, X. L. Hu, Energy Environ. Sci., 2012, 5, 6136-6144.

[35] J. D. Benck, Z. B. Chen, L. Y. Kuritzky, A. J. Forman, T. F. Jaramillo, ACS Catal., 2012, 2, 1916-1923.

[36] Z. Y. Lu, H. C. Zhang, W. Zhu, X. Y. Yu, Y. Kuang, Z. Chang, X. D. Lei, X. M. Sun, Chem. Commun., 2013, 49, 7516-7518.

[37] S. Shin, Z. Y. Jin, D. H. Kwon, R. Bose, Y. S. Min, Langmuir, 2015, 31, 1196-1202.

[38] C. L. Hsu, Y. H. Chang, T. Y. Chen, C. C. Tseng, K. H. Wei, L. J. Li, Int. J. Hydrogen Energy, 2014, 39, 4788-4793.

[39] X. W. Zhang, F. Meng, S. Mao, Q. Ding, M. J. Shearer, M. S. Faber, J. H. Chen, R. J. Hamers, S. Jin, Energy Environ. Sci., 2015, 8, 862-868.

[40] X. B. Ge, L. Y. Chen, L. Zhang, Y. R. Wen, A. Hirata, M. W. Chen, Adv. Mater., 2014, 26, 3100-3104.

[41] T. W. Lin, C. J. Liu, J. Y. Lin, Appl. Catal. B, 2013, 134, 75-82.

[42] D. J. Li, U. N. Maiti, J. Lim, D. S. Choi, W. J. Lee, Y. Oh, G. Y. Lee, S. O. Kim, Nano Lett., 2014, 14, 1228-1233.

[43] A. B. Laursen, P. C. K. Vesborg, I. Chorkendorff, Chem. Commun., 2013, 49, 4965-4967.

[44] Y. J. Sun, C. Liu, D. C. Grauer, J. K. Yano, J. R. Long, P. D. Yang, C. J. Chang, J. Am. Chem. Soc., 2013, 135, 17699-17702.

[45] N. Kornienko, J. Resasco, N. Becknell, C. M. Jiang, Y. S. Liu, K. Q. Nie, X. H. Sun, J. H. Guo, S. R. Leone, P. D. Yang, J. Am. Chem. Soc., 2015, 137, 7448-7455.

[46] N. Jiang, L. Bogoev, M. Popova, S. Gul, J. Yano, Y. J. Sun, J. Mater. Chem. A, 2014, 2, 19407-19414.

[47] L. Yang, X. L. Wu, X. S. Zhu, C. Y. He, M. Meng, Z. X. Gan, P. K. Chu, Appl. Surf. Sci., 2015, 341, 149-156.

[48] Q. Li, Z. C. Xing, D. W. Wang, X. P. Sun, X. R. Yang, ACS Catal., 2016, 6, 2797-2801.

[49] P. Liu, J. A. Rodriguez, J. Am. Chem. Soc., 2005, 127, 14871-14878.

[50] S. T. Oyama, T. Gott, H. Y. Zhao, Y. K. Lee, Catal. Today, 2009, 143, 94-107.

[51] F. H. Saadi, A. I. Carim, E. Verlage, J. C. Hemminger, N. S. Lewis, M. P. Soriaga, J. Phys. Chem. C, 2014, 118, 29294-29300.

[52] Z. Y. Jin, P. P. Li, X. Huang, G. F. Zeng, Y. Jin, B. Z. Zheng, D. Xiao, J. Mater. Chem. A, 2014, 2, 18593-18599.

[53] J. M. McEnaney, J. C. Crompton, J. F. Callejas, E. J. Popczun, A. J. 
Biacchi, N. S. Lewis, R. E. Schaak, Chem. Mater., 2014, 26, 4826-4831.

[54] J. M. McEnaney, J. C. Crompton, J. F. Callejas, E. J. Popczun, C. G. Read, N. S. Lewis, R. E. Schaak, Chem. Commun., 2014, 50, 11026-11028.

[55] S. Gupta, N. Patel, A. Miotello, D. C. Kothari, J. Power Sources, 2015, 279, 620-625.

[56] M. Zeng, H. Wang, C. Zhao, J. K. Wei, K. Qi, W. L. Wang, X. D. Bai, ChemCatChem, 2016, 8, 708-712.

[57] S. Gupta, N. Patel, R. Fernandes, R. Kadrekar, A. Dashora, A. K. Yadav, D. Bhattacharyya, S. N. Jha, A. Miotello, D. C. Kothari, Appl. Catal. B, 2016, 192, 126-133.

[58] A. I. Carim, F. H. Saadi, M. P. Soriaga, N. S. Lewis, J. Mater. Chem. A, 2014, 2, 13835-13839.

[59] X. D. Yan, L. H. Tian, M. He, X. B. Chen, Nano Lett., 2015, 15, 6015-6021.

[60] X. D. Yan, L. H. Tian, X. B. Chen, J. Power Sources, 2015, 300, 336-343.

[61] L. C. Seitz, C. F. Dickens, J. K. Norskov, T. F. Jaramillo, K. Nishio, H. Y. Hwang, Y. Hikita, J. Montoya, A. Doyle, C. Kirk, A. Vojvodic, Science, 2016, 353, 1011-1014.

[62] X. L. Yang, H. N. Li, A. Y. Lu, S. X. Min, Z. Idriss, M. N. Hedhili, K. W. Huang, H. Idriss, L. J. Li, Nano Energy, 2016, 25, 42-50.

[63] T. Reier, Z. Pawolek, S. Cherevko, M. Bruns, T. Jones, D. Teschner, S. Selve, A. Bergmann, H. N. Nong, R. Schlogl, K. J. J. Mayrhofer, P. Strasser, J. Am. Chem. Soc., 2015, 137, 13031-13040.

[64] Y. T. Meng, W. Q. Song, H. Huang, Z. Ren, S. Y. Chen, S. L. Suib, J. Am. Chem. Soc., 2014, 136, 11452-11464.

[65] I. Zaharieva, P. Chernev, M. Risch, K. Klingan, M. Kohlhoff, A. Fischer, H. Dau, Energy Environ. Sci., 2012, 5, 7081-7089.

[66] B. H. R. Suryanto, X. Y. Lu, C. Zhao, J. Mater. Chem. A, 2013, 1, 12726-12731.

[67] J. A. Koza, Z. He, A. S. Miller, J. A. Switzer, Chem. Mater., 2012, 24, 3567-3573.

[68] N. Li, W. Y. Xia, J. Wang, Z. L. Liu, Q. Y. Li, S. Z. Chen, C. W. Xu, X. H. Lu, J. Mater. Chem. A, 2015, 3, 21308-21313.

[69] F. Yan, C. L. Zhu, S. Wang, Y. Zhao, X. T. Zhang, C. Y. Li, Y. J. Chen, J. Mater. Chem. A, 2016, 4, 6048-6055.

[70] M. W. Louie, A. T. Bell, J. Am. Chem. Soc., 2013, 135, 12329-12337.

[71] Y. F. Li, A. Selloni, ACS Catal., 2014, 4, 1148-1153.

[72] D. Friebel, M. W. Louie, M. Bajdich, K. E. Sanwald, Y. Cai, A. M. Wise, M. J. Cheng, D. Sokaras, T. C. Weng, R. Alonso-Mori, R. C. Davis, J. R. Bargar, J. K. Norskov, A. Nilsson, A. T. Bell, J. Am. Chem. Soc., 2015, 137, 1305-1313.

[73] L. Kuai, J. Geng, C. Y. Chen, E. J. Kan, Y. D. Liu, Q. Wang, B. Y. Geng, Angew. Chem. Int. Ed., 2014, 53, 7547-7551.

[74] H. Chen, X. X. Huang, L. J. Zhou, G. D. Li, M. H. Fan, X. X. Zou, ChemCatChem, 2016, 8, 992-1000.

[75] L. X. Wang, J. Geng, W. H. Wang, C. Yuan, L. Kuai, B. Y. Geng, Nano Res., 2015, 8, 3815-3822.

[76] Y. Yang, H. L. Fei, G. D. Ruan, C. S. Xiang, J. M. Tour, ACS Nano, 2014, 8, 9518-9523.

[77] J. Pfrommer, M. Lublow, A. Azarpira, C. Gobel, M. Lucke, A. Steigert, M. Pogrzeba, P. W. Menezes, A. Fischer, T. Schedel-Niedrig, M. Driess, Angew. Chem. Int. Ed., 2014, 53, 5183-5187.

[78] X. Q. Lin, X. Z. Li, F. Li, Y. Y. Fang, M. Tian, X. C. An, Y. Fu, J. Jin, J. T. Ma, J. Mater. Chem. A, 2016, 4, 6505-6512.

[79] A. Indra, P. W. Menezes, N. R. Sahraie, A. Bergmann, C. Das, M. Tallarida, D. Schmeisser, P. Strasser, M. Driess, J. Am. Chem. Soc., 2014, 136, 17530-17536.

[80] R. D. L. Smith, M. S. Prevot, R. D. Fagan, Z. P. Zhang, P. A. Sedach,
M. K. J. Siu, S. Trudel, C. P. Berlinguette, Science, 2013, 340, 60-63.

[81] R. D. L. Smith, M. S. Prevot, R. D. Fagan, S. Trudel, C. P. Berlinguette, J. Am. Chem. Soc., 2013, 135, 11580-11586.

[82] C. J. Zhang, R. D. Fagan, R. D. L. Smith, S. A. Moore, C. P. Berlinguette, S. Trudel, J. Mater. Chem. A, 2015, 3, 756-761.

[83] C. J. Zhang, C. P. Berlinguette, S. Trudel, Chem. Commun., 2016, 52, 1513-1516.

[84] J. Q. Fan, Z. F. Chen, H. J. Shi, G. H. Zhao, Chem. Commun., 2016, 52, 4290-4293.

[85] J. H. Wang, W. Cui, Q. Liu, Z. C. Xing, A. M. Asiri, X. P. Sun, Adv. Mater., 2016, 28, 215-230.

[86] H. B. Li, M. H. Yu, F. X. Wang, P. Liu, Y. Liang, J. Xiao, C. X. Wang, Y. X. Tong, G. W. Yang, Nat. Commun., 2013, 4, 1894.

[87] Y. Q. Gao, H. B. Li, G. W. Yang, J. Appl. Phys., 2016, 119, 034902/1-034902/6.

[88] Y. G. Gao, H. B. Li, G. W. Yang, Cryst. Growth Des., 2015, 15, 4475-4483.

[89] X. Y. Lu, C. A. Zhao, Nat. Commun., 2015, 6, 6616.

[90] Y. Q. Gao, X. Y. Liu, G. W. Yang, Nanoscale, 2016, 8, 5015-5023.

[91] J. W. Nai, H. J. Yin, T. T. You, L. R. Zheng, J. Zhang, P. X. Wang, Z. Jin, Y. Tian, J. Z. Liu, Z. Y. Tang, L. Guo, Adv. Energy Mater., 2015, 5, 1401880

[92] F. Song, X. L. Hu, J. Am. Chem. Soc., 2014, 136, 16481-16484.

[93] B. Zhang, X. L. Zheng, O. Voznyy, R. Comin, M. Bajdich, M. Garcia-Melchor, L. L. Han, J. X. Xu, M. Liu, L. R. Zheng, F. P. G. de Arquer, C. T. Dinh, F. J. Fan, M. J. Yuan, E. Yassitepe, N. Chen, T. Regier, P. F. Liu, Y. H. Li, P. De Luna, A. Janmohamed, H. L. L. Xin, H. G. Yang, A. Vojvodic, E. H. Sargent, Science, 2016, 352, 333-337.

[94] M. W. Kanan, D. G. Nocera, Science, 2008, 321, 1072-1075.

[95] M. Dinca, Y. Surendranath, D. G. Nocera, Proc. Natl. Acad. Sci. USA, 2010, 107, 10337-10341.

[96] A. J. Esswein, Y. Surendranath, S. Y. Reece, D. G. Nocera, Energy Environ. Sci., 2011, 4, 499-504.

[97] D. Gonzalez-Flores, I. Sanchez, I. Zaharieva, K. Klingan, J. Heidkamp, P. Chernev, P. W. Menezes, M. Driess, H. Dau, M. L. Montero, Angew. Chem. Int. Ed., 2015, 54, 2472-2476.

[98] P. Z. Chen, K. Xu, T. P. Zhou, Y. Tong, J. C. Wu, H. Cheng, X. L. Lu, H. Ding, C. Z. Wu, Y. Xie, Angew. Chem. Int. Ed., 2016, 55, 2488-2492.

[99] Y. S. Yang, F. L. Liang, M. R. Li, T. E. Rufford, W. Zhou, Z. H. Zhu, ChemSusChem, 2015, 8, 2193-2197.

[100] H. Y. Jin, J. Wang, D. F. Su, Z. Z. Wei, Z. F. Pang, Y. Wang, J. Am. Chem. Soc., 2015, 137, 2688-2694.

[101] X. X. Yu, T. Y. Hua, X. Liu, Z. P. Yan, P. Xu, P. W. Du, ACS Appl. Mater. Inter., 2014, 6, 15395-15402.

[102] C. Y. He, X. L. Wu, Z. Q. He, J. Phys. Chem. C, 2014, 118, 4578-4584.

[103] Y. H. Liang, X. P. Sun, A. M. Asiri, Y. Q. He, Nanotechnology, 2016, 27, 12LT01/1-12LT01/8.

[104] J. Ryu, N. Jung, J. H. Jang, H. J. Kim, S. J. Yoo, Acs Catal., 2015, 5, 4066-4074.

[105] T. T. Liu, Q. Liu, A. M. Asiri, Y. L. Luo, X. P. Sun, Chem. Commun., 2015, 51, 16683-16686.

[106] X. D. Yan, L. H. Tian, S. Atkins, Y. Liu, J. Murowchick, X. B. Chen, ACS Sustain. Chem. Eng., 2016, 4, 3743-3749. 


\title{
非晶非贵金属催化剂的研究进展及展望
}

\author{
徐文策 ${ }^{\mathrm{a}, \mathrm{b}}$, 王红霞 ${ }^{\mathrm{a}, *}$ \\ a昆士兰科技大学物理化学及机械工程系, 布里斯班, 4001, 澳大利亚 \\ ${ }^{b}$ 天津大学材料科学与工程学院, 天津 30072 , 中国
}

\begin{abstract}
摘要: 近年来电解水产氢作为一种具有前景的制备及储存可再生能源的方法受到了各界的广泛关注. 在此过程中, 电解水 催化剂是提高能源转换效率的关键. 优秀的催化剂应具备高催化活性、高稳定性、低成本以及可大规模生产等性质. 科研 工作者对电解水的两部分反应, 即析氢反应以及析氧反应均进行了广泛及深入的研究. 目前, 贵金属催化剂, 如铂基、钉基 催化剂的催化活性要高于其他元素催化剂, 但由于其价格昂贵, 储量较少使得贵金属催化剂无法得到大规模应用, 因此发 展非贵金属催化剂对绿色能源的发展具有重要意义。一般而言, 催化剂的结晶度越高, 其催化活性越好, 而近年来非晶催 化剂以其更高的催化活性位密度也越来越受到人们的重视. 同时, 非晶催化剂的成分更加灵活, 相比晶体催化剂来说非晶 催化剂可以在更大范围内对成分进行调节. 此外, 非晶催化剂的制备通常都在较为温和的反应条件下进行, 这也能够降低 生成成本, 促进其工业化发展. 在这篇综述里我们介绍了电解水反应的基本原理, 总结了近期非晶析氢、析氧以及双功能 催化剂的研究进展. 并随后探讨了电解水反应目前的难点并对非晶催化剂的制备进行了展望.
\end{abstract}

关键词: 非晶催化剂; 非贵金属材料; 析氢反应; 析氧反应; 全电解水反应

收稿日期: 2017-01-30. 接受日期: 2017-02-28. 出版日期: 2017-06-05.

*通讯联系人. 电话: +61-7-31381984; 传真: +61-7-31388381; 电子信箱: hx.wang@qut.edu.au

本文的英文电子版由Elsevier出版社在ScienceDirect上出版(http://www.sciencedirect.com/science/journal/18722067). 